\title{
ATMOSPHERIC CORROSION DATA OF WEATHERING STEELS. A REVIEW.
}

\author{
M. Morcillo*, B. Chico, I. Díaz, H. Cano, D. de la Fuente \\ National Centre for Metallurgical Research (CENIM-CSIC), Avda. Gregorio del Amo, 8, 28040- \\ Madrid, Spain
}

\begin{abstract}
Extensive information on the atmospheric corrosion of weathering steel has been published in the scientific literature. The contribution of the present work is to provide a bibliographic review of the reported information, which mostly concerns the weathering steel ASTM A-242. This review addresses issues such as rust layer stabilisation times, steady-state steel corrosion rates, and situations where the use of unpainted weathering steel is feasible. It also analyses the effect of exposure conditions. Finally it approaches the important matter of predicting the long-term behaviour of weathering steel reviewing the different prediction models published in the literature.
\end{abstract}

Keywords: A. Low alloy steel; C. Atmospheric corrosion; C. Rust

\section{Introduction}

Weathering steels (WS), also known as low-alloy steels, are steels with a carbon content of less than $0.2 \mathrm{wt}$. \% to which mainly $\mathrm{Cu}, \mathrm{Cr}, \mathrm{Ni}, \mathrm{P}, \mathrm{Si}$ and $\mathrm{Mn}$ are added as alloying elements to a total of no more than 3-5 wt. \% [1]. The enhanced corrosion resistance of WS in relation to mild steel or plain carbon steel (CS) is due to the formation in low aggressive atmospheres of a compact and well-adhering corrosion product layer known as patina.

This definition, however, has not remained unchanged but has evolved as new WS compositions have been developed to achieve improved mechanical properties and/or withstand increasingly aggressive atmospheric conditions from the corrosion point of view, especially in marine environments. The American Society for Testing and Materials (ASTM) has standardised different alloy compositions for WS, from an initial $1.5 \%$ total weight of alloying elements added in the first standardised WS A-242 [2], to 5\% in the last standardised WS A 709-HPS 100W [3], which is at the limit of the composition of intermediate alloy steels. Table 1 sets out the chemical composition of two commonly used WS $[2,4]$.

The patina on WS not only offers greater corrosion resistance than on mild steel, but is also responsible for its attractive appearance and self-healing abilities. The main applications for WS include civil structures such as bridges and other load-bearing structures, road installations, electricity posts, utility towers, guide rails, ornamental sculptures, façades, roofing, etc.

The literature contains a great deal of information on WS, and there are entire chapters in collective works dedicated to this issue, e.g. $[1,5-6]$. However, an in-depth bibliographic

\footnotetext{
${ }^{*}$ Corresponding author: Tel. +34 91553 8900, Fax. +34 915347425 .

e-mail: morcillo@cenim.csic.es (M. Morcillo)
} 
review on the atmospheric exposure data of WS and a rigorous analysis of the published information are lacking. The review presented in this paper seeks to fill this gap.

\section{Brief historical development}

Albrecht and Hall [7] published a complete review on the historical development of WS.

The birth of WS can be traced back to the development of steels containing copper, known as copper steels [8]. In 1910 Buck observed that steel sheets with $0.07 \%$ Cu manufactured by US Steel and exposed in three environments of different corrositivities (rural, industrial and marine) showed a 1.5-2\% greater atmospheric corrosion resistance than CS [9]. Hence, in 1911 US Steel started to market steel sheets with a certain copper content. Buck subsequently reported that the improvement achieved with $\mathrm{Cu}$ concentrations in excess of $0.25 \%$ was insignificant, noting that $0.15 \% \mathrm{Cu}$ provided similar results to $0.25 \% \mathrm{Cu}$ in most cases [10].

Once this capacity of copper steel became known, further research led to the development of WS and thus to High Strength Low Alloy (HSLA) steels [7]. In the 1920's US Steel produced a new family of HSLA steels intended primarily for the railway industry. Finally, in 1933 US Steel launched the first commercial WS under the brand name USS Cor-Ten steel (Early Cor-Ten steel or Cor-Ten B), a name which reflects the two properties that differentiate it from CS, i.e. its corrosion resistance (Cor); and from a copper steel, i.e. its superior mechanical properties (tensile strength, Ten). This product was claimed to provide a $30 \%$ improvement on the mechanical properties of conventional CS, thus reducing the necessary thickness and accordingly the weight of steel to be used for a given set of mechanical requirements [11]. Figure 1 illustrates the corrosion of these three steels in the industrial atmosphere of Kearny and its evolution with time [12]. Attention is drawn to the lower corrosion experienced by the Early Cor-Ten steel.

Early versions of USS Cor-Ten steels were based on Fe-Cu-Cr-P systems, to which $\mathrm{Ni}$ was later added in order to improve corrosion resistance in marine environments. USS Cor-Ten steels presented two specifications, $A$ and $B$, whose main difference lay in the amount of phosphorus present in their composition. USS Cor-Ten A can be said to be the WS with the highest phosphorus content (0.07-0.15\% weight) and USS Cor-Ten B that with the lowest phosphorus content ( $\leq 0.04 \%$ weight) [13].

Greater knowledge of the role played by the different alloying elements $(\mathrm{Cu}, \mathrm{Cr}, \mathrm{Ni}, \mathrm{P}$, etc.) in the atmospheric behaviour of WS was achieved thanks to two ambitious studies carried out in the United States, one began in 1941 by ASTM Committee A-5 [14] and another began in 1942 by US Steel Co. [12]. In the first, 71 low-alloy steels were exposed to the industrial atmosphere at Bayonne, N.J. and to the marine atmospheres at Block Island, R.I. and at Kure Beach (250 m), N.C. In the second study, 270 different steels were exposed in the following atmospheres: South Bend, Pa (semi-rural), Kearny, N.J. (industrial) and Kure Beach (250 m), N.C. (marine).

The current composition of USS Cor-Ten steels has altered to a certain extent, especially in the case of specification $\mathrm{B}$, with the addition of $\mathrm{Ni}(\leq 0.40 \% \mathrm{Ni})$, but they all continue to be marketed to the present day [15-16]. In 1941 the first WS was standardised by ASTM specification A-242; a steel that is roughly comparable to USS Cor-Ten A steel. Its main characteristic is its high resistance to atmospheric corrosion, which is approximately 4 times greater than that of CS due to the presence of copper, a high phosphorus content, and in 
general the presence of nickel $(0.50-0.65 \%)$. However, it is now somewhat obsolete as a structural steel due to the fact that phosphorus can form iron phosphide $\left(\mathrm{FeP}_{3}\right)$ during the welding process, decreasing its weldability and causing the steel to become brittle.

In 1968 ASTM standard A-242 presented two specifications, one with a high phosphorus content $(<0.15 \% \mathrm{P})$ and the other with a lower phosphorus content $(<0.04 \% \mathrm{P})$. The latter was ultimately replaced by ASTM standard A-588 WS [4] (see Table 1), which is roughly comparable to USS Cor-Ten B steel. This steel possesses less resistance to atmospheric corrosion due to its lower $\mathrm{P}$ content, but for this same reason it has better weldability.

Finally, in 1992 the US Federal Highway Administration (FHWA), the American Iron and Steel Institute (AISI) and the US Navy started to develop new improved WS for bridge building, known as High Performance Steels (HPS), and in 1997 the first bridge with HPS-70W was built in Nebraska [17]. Three basic targets were set to improve the overall quality and manufacturability of the steels used hitherto for bridge construction in the United States [18]: (a) improve weldability, achieved by lowering the carbon, phosphorus and sulphur contents; (b) improve mechanical properties, such as fracture toughness and yield strength, achieved by raising the maximum manganese limit; and (c) maintain the formation of protective rust that characterises WS.

\section{Requirements for the formation of protective rust layers on WS}

As has been mentioned, the enhanced corrosion resistance of WS is due to the formation of a dense and well-adhering corrosion product layer.

Experiments carried out in 1969 by Schmitt and Gallagher with low alloy steel (Cor-Ten A) indicated that the texture of the oxide layer was dependent upon the washing action of rainwater and the drying action of the sun [19]. Surfaces sheltered from the sun and rain tended to form a loose and non-compact oxide while surfaces openly exposed to the sun and rain produced strongly adherent layers. On north-facing surfaces the protective layer developed somewhat more slowly as a result of receiving less sunlight. Matsushima et al. [20] subsequently studied the role of a large number of environmental and design variables in the behaviour of WS in architectural applications, verifying the decisive influence on the formation of the protective patina of whether or not the metallic surface was exposed to the rain, or whether or not areas where moisture was liable to accumulate were drained. These effects were more intense in atmospheres with higher pollution levels, in which case the protective patina may not fully form.

Extensive research work has thrown light on the requisites for the protective rust layer to form. It is now well accepted that wet/dry cycling is necessary to form a dense and adherent rust layer, with rainwater washing the steel surface well, accumulated moisture draining easily, and a fast drying action (absence of very long wetness times). Structures should be free of interstices, crevices, cavities and other places where water can collect, as corrosion would progress without the formation of a protective patina. It is also not advisable to use bare WS in continuously moist exposure conditions or in marine atmospheres where the protective patina does not form [5-6, 21].

Therefore, the ability of weathering type steels to fully develop their anticorrosive action is dependent on the climate and exposure conditions of the metallic surface. It must also be 
taken into account that a truly protective oxide film may never develop on certain areas, or that their evolution will be excessively slow.

\section{Atmospheric corrosion data of WS. Worldwide survey.}

Over the years, the first extensive field tests of WS carried out by Copson [14] and LarrabeeCoburn [12] have been followed by further studies all over the world.

A worldwide literature survey has been conducted to obtain data series on WS corrosion versus exposure time [14, 22-55]. Table 2 lists the countries and testing stations where atmospheric exposure studies have been undertaken, as well as some general characteristics of the tests performed.

A factor of uncertainty is that the atmospheres are often classified in purely qualitative terms as rural, urban, industrial or marine, based on subjective assessments of pollution factors. It can also be seen that large amounts of data are available for behaviour in the first 10 years of exposure, but there is notably less information on long-term exposure for more than 20 years.

The bulk of the data refers to ASTM A-242 WS, and as such this is the steel which is particularly referred to throughout this review.

The abundant literature on atmospheric corrosion of weathering steels can sometimes be confusing and lack clear criteria regarding certain concepts that are addressed in the present paper, namely:

(i) How long does it take to reach a steady state (stabilisation of the rust layer) in which the corrosion rate remains practically constant?

(ii) Effect of environmental exposure conditions

(iii) What laws best fit the atmospheric corrosion of WS and estimation (prediction) of longterm atmospheric corrosion?

Each of these issues is addressed below.

\section{Stabilisation of rust layers and steady-state corrosion rate}

Bibliographic information on this aspect is highly erratic and variable, going from claims that a protective patina can be seen to be formed after as little as 6 weeks exposure to reports of stabilisation times of one year, 2-3 years, 8 years, and so forth [56].

Matsushima et al. [20] reported the time required for the corrosion product to stabilise according to its location in the structure and whether the environment was industrial or urban. This time varied from 1 to 5 years, except for locations where stabilisation did not occur due to water pool formation.

The gradual development of a protective layer on WS takes several years before steady-state conditions are obtained. The time taken to reach a steady state of atmospheric corrosion will obviously depend on the environmental conditions of the atmosphere where the steel is exposed.

To determine the stabilisation times of rust layers formed on WS in the different atmospheres, reference has been made to information obtained in the aforementioned bibliographic survey (Table 2). Prior to its analysis the database has been refined by removing all data series which 
have information for only a small number of points (e.g. 1 or 2 points on corrosion rate versus time curves), which correspond to studies that ended after short exposure times ( $<7$ years), or in which it was not possible to determine the stabilisation time due to rising corrosion rates with exposure time, excessively high corrosion rates, etc.

The procedure established to determine rust layer stabilisation times and steady-state corrosion rates has been as follows:

1. The available corrosion rate, $y$, is plotted against the exposure time, $t_{1}$, and fitted to an exponential decrease equation:

$$
y=A_{1} \exp \left(\frac{-x}{t_{1}}\right)+y_{0}
$$

2. Once the equation (1) is obtained, it is used to determine the corrosion rate at different exposure times and to calculate the decrease in the corrosion rate for each annual increment in exposure.

3. A steady state (stabilisation time) is considered to have been reached when the decrease in the corrosion rate for a one-year increment in exposure time is $\leq 10 \%$. (Fig. 2).

4. The steady state corrosion rate is the rate corresponding to the year from which a decrease of $\leq 10 \%$ takes place (Fig. 2).

With the information selected in this way, tables 3 and 4 have been prepared for non-marine (rural, urban and industrial) and marine atmospheres respectively, listing the testing stations in order of corrosivity categories according to ISO 9223 [57], obtained from corrosion data for CS after one year of exposure.

The tables contain the following information: ISO corrosivity category (ISO 9223), site and country, first-year CS corrosion $(\mu \mathrm{m})$, stabilisation time (years), steady-state corrosion rate $(\mu \mathrm{m} / \mathrm{y})$, max. exposure time (years) and type of WS according to ASTM specifications.

Box-whisker plots obtained from statistical processing of the stabilisation times and steadystate corrosion rates for ASTM A-242 WS shown in tables 3 and 4 are presented in figures 3 to 5. The box-whisker type graph represents the statistical data as separate boxes. The box is determined by the 25th and 75th percentiles, and the band inside the box is the median (50th percentile). The ends of the whiskers are determined by the minimum and maximum of all of the data. The small square symbol inside the box is the mean value of the data and $x$ symbols, the 1st and 99th percentiles. These figures reveal the following trends:

(i) The stabilisation time of the rust layer decreases as the corrosivity category of the atmosphere where the WS has been exposed rises (Fig. 3), going from 6-8 years in less aggressive atmospheres to 4-6 years in more corrosive atmospheres.

The stabilisation time of the rust layers depends, among other factors, on the exposure time, the existence of wet/dry cycles, the corrosivity of the atmosphere, and in short on the volume of corrosion products formed. However, a shorter stabilisation time does not imply a greater protective capability of the rust. In this respect, the stabilisation of the rust layer occurs faster in marine atmospheres due to their greater corrosivity, but 
the protective value of this rust is lower than that of rusts formed in non-marine atmospheres (rural, urban and light industrial) where the stabilisation times are longer.

(ii) The steady-state corrosion rate rises in line with the corrosivity of the atmosphere in both rural, urban and industrial atmospheres (Fig. 4) and marine atmospheres (Fig. 5).

A matter of the greatest practical relevance is to know when an unpainted WS can be used. The cost of painting a CS bridge usually represents around $12 \%$ of its initial construction cost, with repainting taking place every 6 to 15 years, depending on the aggressivity of the environment to which it is exposed. WS structures normally become more economical than painted CS structures [58] after 15 years in service in environments of moderate aggressivity.

The problem is how to define the environmental conditions of an atmosphere of moderate aggressivity, which is ultimately what determines the applicability of an unpainted WS. From a practical point of view, the criterion followed has been to limit the steady-state corrosion rate of WS in the atmosphere to an acceptable value for material safety, where maintenance operations are not required [59]. Thus, in 1960, after a 15-year atmospheric corrosion test, Larrabee and Coburn [12] suggested that $\leq 5$ $\mu \mathrm{m} /$ year was an acceptable corrosion rate for the use of unpainted WS. In Japan unpainted WS can be used for bridge construction in environments where the corrosion loss is $\leq 6 \mu \mathrm{m} /$ year for the first 50 years of exposure [60], although this criterion has subsequently become more restrictive, and their use is now only advised in environments where the corrosion loss is $\leq 5 \mu \mathrm{m} /$ year for the first 100 years of exposure [61]. In the USA, Cook [62] reported that the use of unpainted WS was acceptable in places with an average corrosion of up to $120 \mu \mathrm{m}$ in the first 20 years of exposure, i.e. a corrosion rate of $\leq 6 \mu \mathrm{m} /$ year.

The fairly widespread criterion of $\leq 5-6 \mu \mathrm{m} /$ year for long-term atmospheric corrosion suggests only a marginal benefit of using conventional WS in preference to CS in aggressive atmospheres, especially in marine atmospheres [63]. A view of figures 4 and 5 , which plot a steady-state corrosion rate of $6 \mu \mathrm{m} / \mathrm{year}$, indicates that unpainted conventional WS should not be used in atmospheres of corrosivity category $\geq C 3$, marine or otherwise.

(iii) With regard to the corrosion resistance of the two traditionally most widely used WS, ASTM A-242 and ASTM A-588, view of tables 3 and 4 reveals that ASTM A-588 exhibits poorer corrosion resistance than ASTM A-242 (its steady-state corrosion rates are 50$100 \%$ higher than those of ASTM A-242) and a shorter exposure time in the atmosphere before stabilisation of the rust layer.

\section{Effect of exposure conditions}

The corrosion characteristics of WS depend in a complex way on climate parameters, pollution levels, exposure conditions (open air, shelter, etc.) and the composition of the steel.

With regard to the effect of exposure conditions on the atmospheric corrosion of WS, only a limited amount of information is available. In this respect it is interesting to cite the work carried out by K. Park in 2004 [64], which makes an exhaustive bibliographic review 
considering design aspects such as: angle of exposure depending on the latitude of each site, skyward or groundward orientation, sheltered conditions, continuous moisture conditions, and heavy concentrations of pollutants from rainfall or salt spray, deicing salts, dirt, and debris in industrial and marine environments, etc.

In order for patinas with optimum protective properties to develop, the environmental conditions must act in the appropriate way on the metal surface. In this sense, as has been noted above, it is important that rainwater washes the steel surface well, that accumulated moisture is well-drained, and that drying action is fast. A key condition for the formation of a protective patina is a cyclical variation between wet and dry periods. Periodic flushing followed by drying is desirable. In rain-sheltered areas, the typical dark patina formed on open exposure is not obtained and instead the surface becomes coated with a layer of lighter-coloured rust. Nevertheless, the rust layers are more compact and adherent than on CS and the corrosion rate is usually so low that the absence of dark patina seems to be of only aesthetic significance [32]. An exception is atmospheres with high chloride contents, where the accumulation of hygroscopic chlorides can give rise to very high corrosion rates [65].

\subsection{Geometry of exposure}

The good performance of WS, low corrosion rate, good surface appearance, and early formation of protective rust films, depend on the geometry of exposure which determines a good washing action of rainwater and easy drainage of moisture. Thus, Matsushima et al. [20] by means of periodic observations of the appearance of rust and corrosion rate measurements showed that good washing of the surface by rainwater was the most important effect for the early development of a protective rust film.

Larrabee [66] and Schikorr [67] noted the importance of the orientation and geometrical configuration of specimens in field exposure tests, i.e. the angle with respect to the horizontal, and differences between the upper and lower sides of the specimens, due primarily to the time of wetness and amount of deposition.

The orientation and angle of exposure significantly affect the corrosion rate. To obtain comparable results, ASTM practice G50 [68] recommends exposing specimens at an orientation and an angle that yield the least amount of corrosion. This condition is met in the northern hemisphere when the sun is above the equator and the specimens face south at an angle equal to the latitude of the test site. Conversely, in the southern hemisphere, specimens should be exposed facing north at an angle equal to the latitude of the test site. Most atmospheric corrosion tests in the United States have been performed at an angle of $30^{\circ}$ facing south. However, atmospheric corrosion studies in Europe are usually done with specimens facing south at $45^{\circ}$ from the horizontal, owing to the higher latitudes.

\subsubsection{Angle with respect to the horizontal}

Several researchers have addressed this issue. In 1951 Laque [69] noted that specimens exposed vertically do not develop protective rusts as those exposed at an angle of $30^{\circ}$, especially in the very severe environment close to the ocean. Laque concluded that vertical exposure has the disadvantage that a few degrees variation from the specified $90^{\circ}$ will have a much greater effect on the extent to which the surfaces are shaded than a similar variation from a specified $30^{\circ}$ position. In 1966 Larrabee [70] also reported that the angle relative to the 
horizontal at which specimens are exposed to the environment affected the corrosion rate of WS.

Coburn et al. [41] presented results obtained after 16 years of exposure of ASTM A-588 Gr.A (originally Cor-Ten B) WS specimens in different atmospheres at two different angles, $30^{\circ}$ and $90^{\circ}$ (vertical), concluding that exposure at $30^{\circ}$ led to lower corrosion rates. These results were consistent with those previously reported by Laque [69] and Larrabee [70]. Meanwhile, Coburn et al. noted that WS specimens exposed facing south showed lower corrosion rates than those facing north due to the fact that direct solar radiation from the south resulted in a shorter time of wetness [41].

Studies carried out by Cosaboom et al. [71] confirm the observations of Coburn et al. [41]. While Cosaboom et al. found that $0^{\circ}$ (horizontal) specimens corroded less than $90^{\circ}$ (vertical) specimens because they washed and dried within a short time after rainfall, Zoccola et al. [72], in a study carried out in Detroit, noted the reverse to be true, with horizontal specimens corroding more than vertical specimens. Zoccola et al. noted that the test site was subject to the accumulation of road dirt and salts on the steel surfaces, and the horizontal specimens were easily contaminated, promoting prolonged wetness and accelerating steel corrosion rates. Thus, special attention must be paid to horizontal surfaces where hygroscopic deposits, chlorides and sulphates, may accumulate and prolong the time during which the surface is wetted.

The effect of panel orientation was studied also by Knotkova et al [32]. Based on the appearance of the surfaces, the rust found on the specimens facing south, west, and east had an attractive fine texture and dark colour and was comparable in all three orientations. The horizontal specimens were different in appearance: the WS had a light-coloured, coarsetextured but adherent rust layer while the rust on the CS was flaking off locally. Gravimetric measurements revealed that eastward exposure was the most aggressive. Moisture probably dried more slowly on the east-facing specimens and this increased the time during which active corrosion occurred. The largest difference between WS and CS was seen on the southfacing specimens.

\subsubsection{Orientation}

Larrabee [66] and Zoccola [73] showed that the skyward or groundward orientation of the specimen can affect the atmospheric corrosion rate of WS. The upper surface of steel specimens is generally expected to be wet for a shorter time than the lower surface, which receives no sunshine. In this respect, Oesch and Heimgartner [74] noted that rust on the lower side of a WS exposed to an atmosphere polluted with $\mathrm{SO}_{2}$ presented a higher concentration of sulphate nests, while the rust formed on the upper side was more compact with fewer flakeoffs.

In a study of geometrical factors, Moroishi and Satake [75] assessed the upper and lower sides of CS and WS specimens using specimens with one side painted that were exposed at various angles and directions. The lower side tended to corrode as much as $60-70 \%$ more than the upper side, and the extent of corrosion increased as the orientation approached the vertical. These observations correlated with the sulphate concentration in corrosion product layers on specimens that were only exposed on their lower side. On the other hand, specimens whose 
upper sides were also exposed behaved differently because of the washout caused by rainfall. These corrosion phenomena were more prominent for carbon steel than for weathering steel.

Knotkova et al. [32] also measured the corrosion rate separately on the upper and lower sides of CS specimens during exposure in a southerly orientation at an exposure angle of $45^{\circ}$ from the horizontal. The 7-year results showed a relative retardation of the corrosion process on the lower sides of the specimens, but this conclusion cannot necessarily be applied to all exposures. In cases where large structures are exposed and ventilation conditions are different on downward-facing surfaces, corrosion rates will be substantially different to those noted for standard panels in atmospheric exposure sites.

\subsubsection{Other design parameters}

Important studies of design parameters and the formation of protective corrosion product layers were conducted by Satake et al. [76] and Matsushima et al. [20] in 1970 and 1974, respectively. These researchers constructed models with the anticipated configurations of WS structures: H-shaped pillars and beams, ceilings, window frames, siding, louvers and stairs. They point out that during the design and maintenance of WS, special attention must be paid to crevice areas that can retain moisture much longer time than open surfaces and in which more aggressive electrolytes may form.

\subsection{Environmental conditions}

It is of interest to know the effect of climate and pollution variables on the corrosion resistance of WS.

\subsubsection{Outdoor exposure}

The literature contains abundant references and representations of corrosion versus time for WS exposed in atmospheres of different types: rural, urban, industrial and marine. Figure 6 is an example of this. Such information, however, presents a factor of uncertainty in that the atmospheres are classified in a purely qualitative way according to the location of the testing station and its surroundings, based on a subjective assessment of climate and pollution factors.

According to Knotkova et al. [32], in rural areas the corrosion rate is usually low, and the time needed to develop a protective and nice-looking patina may be quite long. For CS the corrosion rate is also rather low in these conditions (Fig. 7).

In urban environments with $\mathrm{SO}_{2}$ levels not exceeding about $90 \mathrm{mg} \mathrm{SO} / 2 \mathrm{~m}^{2} . \mathrm{d}$, WS usually show stabilised corrosion rates in the range of 2-6 $\mu \mathrm{m} /$ year, i.e. only slightly higher than in rural atmospheres. CS shows markedly higher corrosion rates in these conditions (Fig. 7).

In more polluted industrial atmospheres with $\mathrm{SO}_{2}$ levels exceeding $90 \mathrm{mg} \mathrm{sO} / \mathrm{m}^{2} . \mathrm{d}$, significantly higher corrosion rates are also found for WS (Fig. 7), indicating that the rust layer formed at very high $\mathrm{SO}_{2}$ pollution is not altogether protective [32]. Although the surface coating may have a dark, pleasant appearance, it cannot be classified as a true patina. In these conditions loose rust particles are also formed. However, the corrosion rate has always been found to be less than that of CS in these environments.

In marine environments polluted with chlorides a protective patina does not develop and the corrosion rate may be high, especially close to the shore. This applies especially to rain- 
sheltered surfaces, where the corrosion rate may be very high due to the accumulation of chlorides which are never washed away.

\subsubsection{Indoor exposure}

In indoor exposure no systematic differences have been observed between WS and CS corrosion rates. The low corrosion rates observed in all cases were due to the low corrosivity of the environment and not the steel composition. Thus, in agreement with Knotkova [32], there is no justification for using WS in indoor conditions.

\subsubsection{Shelter exposure}

The majority of long-term exposure trials showing the advantages of WS have been carried out in open exposure conditions where the test specimens are freely exposed to the action of rain, wind, and sunshine. However, a large part of all steelwork is sheltered from any direct action of rain and sunshine and it is questionable whether the results from open exposure testing can be applied to sheltered steelwork. Unfortunately, little information is available on corrosion rates in sheltered conditions.

Larrabee [70], Zoccola [73], Cosaboom et al. [71] and Mckenzie [77] conducted tests with both sheltered and open exposure to clarify the effect of sheltering on WS corrosion. Sheltered racks were used for the experiment by Larrabee and Zoccola, whereas Cosaboom et al. conducted experiments by attaching the specimens on an interior girder to achieve a sheltered effect, and on a roof of a building to simulate open exposure. Mckenzie also examined specimens on an interior girder, and exposed a set of specimens not on a roof but in the open, facing prevailing winds.

Larrabee [70] was the first researcher to carry out tests involving partly and completely sheltered test specimens facing north, south, east and west. He found that for a rural site there were only relatively small variations in weight loss that could be attributed to the amount of sheltering and direction of exposure, although sheltered specimens generally had considerably higher corrosion rates than freely exposed specimens. At a marine site he found that fully sheltered specimens corroded more than partly sheltered specimens. This was attributed to the better washing action of rain on the chloride deposits on partly sheltered specimens. However, in later tests at the same site the opposite was found, with fully sheltered specimens corroding less than partly sheltered specimens.

Although the relevance of such information to the particular sheltering of a composite highway bridge is clearly limited, a paper analysing the applicability of results of long-term corrosion tests with WS to the corrosion of highway bridges concluded that steel specimens sheltered from direct rain or sunlight would corrode more than steel fully exposed [78].

In the research carried out by Zoccola [73], vertical specimens were attached on an interior girder of a bridge located on an industrial site and on the roof of a building near the bridge. WS was two times more corroded on sheltered interior girders than in open exposure. It was argued that WS exposed to traffic fumes, road salt and dirt caused the specimens to develop heavy, flaky rust and a significant accumulation of deposits.

Cosaboom et al. [71] mounted specimens vertically and horizontally on interior and exterior girders of a bridge closed to traffic and on the roof of a nearby building on an industrial site. 
Both the vertical and horizontal bridge-sheltered specimens lost up to $65 \%$ more thickness than those openly exposed on the building roof. Moreover, vertical specimens corroded more on interior girders than on exterior girders while horizontal specimens corroded almost the same on interior and exterior girders.

After 5 years of testing at a rural site McKenzie [77] found little indication of a reduction in the corrosion rate with time in sheltered conditions. In the absence of high chloride levels, corrosion was lower in bridge sheltering than in open exposure. However, in sheltered marine environments the corrosion rates of WS were higher and severe pitting developed.

\subsubsection{Continuously moist exposure}

In conditions with very long wetness times or permanent wetness, such as exposure in water or soil, the corrosion rate for WS is usually about the same as for CS.

The results of experiments carried out by Larrabee [70] showed that the amount of corrosion loss on WS and CS was high in the wet tunnel where the steels remained continuously moist; especially with water of a low $\mathrm{pH}$, the WS did not perform well in open exposure. The atmosphere in the wet tunnel was so severely corrosive that after one year of exposure the thickness loss of WS was more than 11 times that of the same steel exposed on the roof.

\subsubsection{Air-borne pollutants}

One of the factors affecting steel corrosion is industrial pollution produced by the burning of fossil fuels. Atmospheric corrosion increases strongly if the air is polluted by smoke gases, particularly sulphur dioxide, or aggressive salts, as in the vicinity of chimneys and marine environments. Atmospheric corrosion is therefore particularly strong in industrial and coastal areas. Corrosion is furthermore much higher if the metal surface is covered by solid particles, such as dust, dirt, and soot, because moisture and salts are then retained for a long time [79].

According to Singh et al. [80], both $\mathrm{SO}_{2}$ and chlorides change the structure and protective properties of the rust layer.

\subsubsection{Sulphur dioxide $\left(\mathrm{SO}_{2}\right)$}

Particular mention should be made of the effect of atmospheric $\mathrm{SO}_{2}$ pollution on WS corrosion, where the existing literature is rather confusing. While some authors argue that WS are less sensitive to $\mathrm{SO}_{2}$ than $\mathrm{CS}$, especially for long exposure time, others believe that WS need access to $\mathrm{SO}_{2}$ or sulphate-containing aerosols to improve their corrosion resistance or report that a low but finite concentration of $\mathrm{SO}_{2}$ in the atmosphere can actually assist the formation of a protective layer on WS [6].

ISO 9223 [57] notes that "in atmospheres with $\mathrm{SO}_{2}$ pollution a more protective rust layer is formed". Leygraf and Graedel [6] considers that a certain amount of deposited $\mathrm{SO}_{2}$ or sulphate aerosols is beneficial for the formation of protective patinas on the surface of WS, but large amounts result in intense acidification of the aqueous layer, triggering dissolution and hindering precipitation.

\section{(a) Open exposures}

Studies into the effect of $\mathrm{SO}_{2}$ pollution in the atmosphere on WS corrosion are very scarce. Perhaps one of the first studies in which this matter has been directly addressed 
is that carried out by Satake and Moroishi [81], who exposed specimens of a low-alloy steel in a network of 12 stations throughout Japan. These authors found a close relationship between first year corrosion losses and the $\mathrm{SO}_{2}$ concentration in the air, but this relationship was not clearly seen after five years.

Apart from this worthy attempt by Satake and Moroishi, the fact is that few studies have been carried out (supported by an extensive experimentation) to determine the relationship between the atmospheric $\mathrm{SO}_{2}$ content and WS corrosion.

Knotkova et al. [32] carried out a field study in different atmospheres, cited above, to determine the effect of $\mathrm{SO}_{2}$ on the atmospheric corrosion of an ASTM A-242 type WS with the denomination "Atmofix" (see Fig. 7), and the following considerations were made:

(i) In rural and urban atmospheres with low pollution levels, i.e. $\mathrm{SO}_{2}$ levels of about 40 $\mathrm{mg} / \mathrm{m}^{2}$.day or less, the conditions are suitable for the formation of a highly protective rust layer on low-alloy steels leading eventually to a relatively stable low rate of corrosion. The appearance of the rust layer on WS is characterised by an attractive dark brown to violet colour and a compact structure.

(ii) In more polluted urban and industrial atmospheres, where the annual average pollution level reaches up to $90 \mathrm{mg} / \mathrm{m}^{2}$.day, the rust layer formed on WS is again dark brown to violet, but its structure is coarser than that observed in rural atmospheres. It is likely that at certain times of the year the higher $\mathrm{SO}_{2}$ content, coupled with higher humidity, causes local cracking and spalling of the rust layer, requiring the layer to reform in these areas.

(iii) For heavily polluted industrial atmospheres where the $\mathrm{SO}_{2}$ level is high, the results indicate a higher corrosion rate than is generally seen on WS with a stable rust layer. This indicates that the process of spalling and regrowth of the rust layer is occurring regularly and intensively.

According to Knotkova et al. [32] the corrosion of WS must be a constant function of the $\mathrm{SO}_{2}$ content, increasing as the $\mathrm{SO}_{2}$ content rises. For this reason it was desirable to specify a maximum $\mathrm{SO}_{2}$ level in the atmosphere where WS may be used without protective coatings. Detailed analysis of the data set of long-term test results, supplemented by the results of 3-year tests in the North Bohemian network of stations with more finely graduated $\mathrm{SO}_{2}$ levels, was very helpful to more precisely define the critical $\mathrm{SO}_{2}$ level. The results of this analysis indicate a maximum annual average $\mathrm{SO}_{2}$ content of $90 \mathrm{mg} / \mathrm{m}^{2}$.day. A summary plot showing this analysis is given in Fig. 8 .

It seems that $90 \mathrm{mg} \mathrm{sO} / \mathrm{m}^{2}$.day, the limit established by Knotkova et al. [32] may perhaps be excessive. In accordance with the steady-state corrosion rate criterion of 6 $\mu \mathrm{m} /$ year (see chapter $5(\mathrm{ii})$ ), which is widely accepted to consider that unpainted WS may be used, Fig. 9 has been prepared from data obtained in a 8-year study performed at numerous locations within the framework of the UN/ECE International Cooperative Programme on effects on materials, including historic and cultural monuments [26]. Figure 9 shows that the steady-state corrosion rate of $\leq 6 \mu \mathrm{m} /$ year is obtained for atmospheric $\mathrm{SO}_{2}$ contents of less than $20 \mathrm{mg} \mathrm{SO} / 2 \mathrm{~m}^{2}$.day. Above this $\mathrm{SO}_{2}$ level WS 
corrosion is accelerated. These results seem to confirm the opinion of Leygraf and Graedel that large amounts of deposited $\mathrm{SO}_{2}$ result in intense acidification of the aqueous layer existing on WS during the corrosion process triggering dissolution and hindering precipitation [6].

(b) Sheltered exposures

The results obtained by Knotkova et al. [33] for shed exposures (Stevenson screen) after 5 -year tests on WS specimens yielded the following conclusions:

(i) The rust that forms on WS in shed exposures does not develop the protective quality found in normal exposure to the weather, and

(ii) The most favourable conditions for WS application came from urban shed exposures. WS corrosion losses at the same localities were lower than those of CS, and locations with good ventilation proved to be especially favourable; e.g. the lower decks of bridges and open galleries. Even though the rust layers in these cases never had the typical appearance of exterior exposures, they were more compact and more adherent on WS than on CS. The difference in steady-state corrosion rates is relatively low, so the final corrosion rates cannot be a motivation for using WS instead of CS.

Table 5 has been prepared using data obtained in a more recent study carried out in the framework of the UN/ECE exposure programme [26], where ASTM A-242 WS specimens were exposed to the open air and inside ventilated boxes (shelters). The steady-state corrosion rate has been calculated, according to the procedure mentioned above in chapter 5, for different testing stations in the two exposure conditions: open air and shelter.

In atmospheres of low corrosivity, where first year CS corrosion remains below $40 \mu \mathrm{m}$, the steady-state corrosion rate in sheltered conditions is similar to or less than that corresponding to open air exposure. However, when the first year CS corrosion is higher than $40 \mu \mathrm{m}$, the WS corrosion rate in sheltered exposure exceeds that found in open air exposure. In these atmospheres the $\mathrm{SO}_{2}$ content in the atmosphere is higher, promoting greater steel corrosion in sheltered conditions due to moisture retention and the absence of wash-off by rainwater.

\subsubsection{Sea chlorides}

If bibliographic information on the effect of $\mathrm{SO}_{2}$ on the atmospheric corrosion of WS is scarce, data analysing the effect of atmospheric salinity in marine atmospheres is even scarcer.

The only rigorous study found in the literature was carried out in Japan on 41 bridges through long-term exposure tests ( 9 years) between 1981 and 1993 by three organisations: the Public Works Research Institute of the Construction Ministry, the Japan Association of Steel Bridge Construction, and the Kozai Club [60]. Figure 10 shows the relationship between atmospheric salinity and WS corrosion, differentiating between two zones according to the adherent or non-adherent nature of the rust formed. 
There seems to be a critical air-borne salinity concentration of around $3 \mathrm{mg} \mathrm{Cl} / \mathrm{m}^{2}$.day $(0.05$ $\mathrm{mg} \mathrm{NaCl} / \mathrm{dm}^{2}$.day) below which the steady-state corrosion rate of conventional WS is less than $6 \mu \mathrm{m} / \mathrm{year}$, the criterion already mentioned for allowing the use of unpainted WS.

\subsubsection{Deicing salts}

Extensive use of deicing salts for snow removal, such as sodium chloride $(\mathrm{NaCl})$ and calcium chloride $\left(\mathrm{CaCl}_{2}\right)$, began in the early 1960s. The common use of salt has been associated with a significant amount of damage to the environment and highway structures (Murray 1977) [82]. Albrecht and Naeemi [83] list the different ways in which salt contaminates the steel structure.

In the literature it is possible to find results which indicate that specimens at interior and fascia girders were more corroded than roof specimens because of contamination by salt and water from the bridge deck during the winter season [71], and results obtained by Zoccola [73] which show that road spray, dirt and salts were carried by the air blast created by the heavy traffic on the expressway and quickly contaminated horizontal specimens. The prolonged wet period caused by deposits, chlorides and sulphates in close contact with the steel tended to accelerate poultice corrosion.

Other references related with this point include Park [64] and Hein and Sczyslo [84]. The results of the latter study showed that more corrosion occurred in freezing weather, especially on the highway. In the turbid and freezing weather of Merklingen, ASTM A-588 WS corrosion on the highway showed no difference from CS corrosion. In contrast, the corrosion rates for WS and CS attached to the guardrail along the highway in Duisburg, where it was sunny and warm, were comparably lower than in Merklingen.

\subsubsection{Other specific microclimates}

Results obtained by Knotkova et al. [33] in microclimates of chemical plants, agricultural areas, metallurgical and textile production plants, as well as in automotive and streetcar environments, showed that WS are generally not suited for such applications and their applicability must be established by experimental results in each specific case.

\section{Long-term atmospheric corrosion of WS}

As the use of WS in civil engineering became more common, it became necessary to estimate in-service corrosion penetration.

The following approaches can be used to predict the corrosion of WS:

a) Direct reference to experimental data in the literature on the behaviour of these steels in rural, urban, industrial and marine environments after different time periods, considering the most similar atmospheres to the site of the planned structure.

b) Taking estimations made for CS and adapting them to WS, applying a reduction coefficient $(R)$ that must logically vary with exposure time and conditions.

c) Based on empirical formulae similar to those developed for CS.

For approach a) it will be necessary to use the broadest possible compilation of corrosion data for WS in a diversity of circumstances. Table 2 presents a compendium of information found in the literature which may be of assistance in this respect. As has been pointed out before, a factor of uncertainty is that atmospheres are generally classified in purely qualitative terms, 
based on a subjective assessment of corrosion factors. Moreover, despite the profusion of data on behaviour in the first 10-20 years of exposure, there is a notable lack of information for exposure beyond 20 years.

In this approach could be also of interest to predict atmospheric corrosion resistance of a WS according to its composition, i.e. the presence and proportion of each alloying element in the alloy. This issue is addressed by ASTM standard G101 [85]. For this purpose the standard establishes two corrosion resistance indices based on two sources of historic atmospheric corrosion data for WS, one published by Larrabee and Coburn [12] and the other by Townsend [86]. Basically it consists of fitting the historic corrosion mass loss data to the typical bilogarithmic equation (see Section 7.1.1), and after statistical analysis to obtain an index (for each historic data source) in the form of an equation in which alloying elements are independent variables.

Both indices are dimensionless, on a scale that goes from zero (no resistance to atmospheric corrosion) to 10 (high resistance to atmospheric corrosion).

ASTM standard G101 is currently the only available guide to quantify the atmospheric corrosion resistance of WS as a function of their composition. However, its predictions need to be taken with a degree of caution due to a series of limitations that affect the standard [87]. Thus, for instance, the atmospheric corrosion resistance index obtained from the mass loss data of Larrabee and Coburn [12] cannot be used as a method to predict corrosion for other WS with a different alloying composition. And on the other hand, the atmospheric corrosion resistance index obtained from the historic mass loss data reported by Townsend [86], who used a wider compositional range and a larger number of alloying elements, presents the disadvantage that atmospheric exposure was carried out only in industrial environments, although this does not necessarily prevent the behaviour prediction from being transferable to other types of atmospheres.

With regard to approach $b$ ), the information obtained in the worldwide survey (see chapter 4) has been used to prepare Table 6 , which shows the relationship $(R)$ between corrosion rates for WS and the corresponding to CS when the rust layer stabilisation time has been reached on these two materials. $\mathrm{R}$ is not seen to vary greatly according to the corrosivity of the atmosphere, and remains in the 0.3-0.5 range, indicating a notable reduction in the atmospheric corrosion of steel when using WS.

Finally, with regard to approach c), it is first necessary to examine what laws fit better the behaviour of weathering steels.

\subsection{Models governing the evolution of atmospheric corrosion of WS with exposure time (time- dependent models)}

\subsubsection{Power model}

As Bohnenkamp et al. noted in 1974 [35], the corrosion curves of low-alloy steels, like those of mild and carbon steels, are reminiscent of the typical plot of parabolic laws or power functions (Fig. 6).

Thus, most of the experimental atmospheric corrosion data has been found to adhere to the following kinetic relationship: 


$$
C=A t^{n}
$$

where $C$ is the corrosion after time $t$, and $A$ and $n$ are constants.

Thus, corrosion penetration data is usually fitted to a power model involving logarithmic transformation of the exposure time and corrosion penetration.

$$
\log C=\log A+n \log t
$$

This power function (also called the bilogarithmic law) is widely used to predict the atmospheric corrosion behaviour of metallic materials even after long exposure times, and its accuracy and reliability have been demonstrated by a great number of authors: Bohnenkamp et al. [88], Legault and Preban [50], Pourbaix [49], Feliu and Morcillo [89], and Benarie and Lipfert [90], among others.

If the parabolic law is fulfilled, corrosion behaviour will clearly be characterised by only two parameters: corrosion $A$ after the first year of exposure and the time exponent $n$. When $A$ and $n$ are known for a given steel and exposure site, the predictions may be extended to any length of time. The value of $n$ does not affect first year corrosion but corrosion in successive years, and its contribution becomes increasingly important; even when the first year corrosion $(A)$ is greater in one place than in another, it is perfectly possible for the order of importance of the corrosion process to be reversed after a number of years due to differences in the value of $n$.

Pourbaix [49] also stated that the bilogarithmic law is valid for different types of atmospheres and for a number of materials and is helpful in extrapolating corrosion results up to 20-30 years from four-year test results.

The value of exponent $n$ can serve as a diagnostic tool to indicate the nature of the relationship: linear $(n=1)$, parabolic $(n=0.5)$, cubic $(n=0.33)$, etc. This is usually explained in terms of deviation from parabolic behaviour as a result of changing diffusion conditions as the film grows [50].

According to Benarie and Lipfert [90], equation (2) is a mass-balance equation showing that the diffusion process is rate-determining, and this rate depends on the diffusive properties of the layer separating the reactants. The exponential law, equation (2), with $n$ close to 0.5 , can result from an ideal diffusion-controlled mechanism when all the corrosion products remain on the metal surface. This situation seems to occur in slightly polluted inland atmospheres. On the other hand, $n$ values of more than 0.5 arise due to acceleration of the diffusion process (e.g. as a result of rust detachment by erosion, dissolution, flaking, cracking, etc.). This situation is typical of marine atmospheres, even those with low chloride contents. Conversely, $n$ values of less than 0.5 result from a decrease in the diffusion coefficient with time through recrystallisation, agglomeration, compaction, etc. of the rust layer.

As a rule, $n<1$. In the special case when $n=1$, the mean corrosion rate for one-year exposure is equal to $A$, the intersection of the line on the bilogarithmic plot with the abscissa $t=1$ year. There is no physical sense in $n>1$, as $n=1$ is the limit for unimpeded diffusion (high permeable corrosion products or no layer at all). Values of $n>1$ occur practically as exceptions, due to outliers in the weight loss determinations.

The lower $n$ is, the more protective the corrosion product layer on the metal surface is. Therefore, $n$ could be used as an indicator for the physico-chemical behaviour of the corrosion 
layer and hence for its interactions with the atmospheric environment. The value of $n$ would thus depend both on the metal concerned, the local atmosphere, and the exposure conditions.

On the other hand, the parameter A provides a criterion for gauging short-term atmospheric corrosion susceptibility. It provides a measure of the inherent reactivity of a metal surface as reflected in the tendency for that surface to produce a corrosion product layer in short-term atmospheric exposure [91].

On the basis of Eq. (2), Townsend and Zoccola [42] use as an indicator of the atmospheric corrosion of different WS the time to exhibit a loss of $250 \mu \mathrm{m}$ calculated by solving Eq. (2) for time:

$$
t^{*}=\left(\frac{C^{*}}{A}\right)^{\frac{1}{n}}
$$

where $t^{*}$ is the time in years to achieve a $250 \mu \mathrm{m}$ corrosion loss; $C^{*}$ is the selected corrosion loss $(250 \mu \mathrm{m})$, and $A$ and $n$ are constants of $\mathrm{Eq}(2)$.

Using the information obtained in the literature survey (chapter 4) we have represented using bilogarithmic coordinates the graphs of the evolution of WS corrosion with exposure time, subsequently calculating the exponent $n$ and the correlation coefficient $(\rho)$. Tables 7 and 8 show the results obtained in non-marine and marine atmospheres, respectively. In the vast majority of the stations the data is well adapted to straight lines with high correlation coefficients.

By way of example, Fig. 11 displays on a bilogarithmic scale the evolution of the atmospheric corrosion of ASTM A-242 WS in different types of atmospheres. As can be seen, the points are almost perfectly aligned and the correlation coefficients are fairly close to unity.

The data series do not adapt well to this rule in only a small percentage of cases with regression lines that present lower correlation coefficients (Fig. 12).

Statistical processing of the $n$ slopes as a function of the type of atmosphere (Fig. 13) shows the clear tendency of marine atmospheres to present higher average $n$ values (close to 0.5) than atmospheres without a marine component, where $n$ presents an average value of around 0.3 , irrespective of the atmospheric corrosivity category of the exposure site.

Table 9 lists the average values of $n$ for CS and WS in different types of atmospheres. This data may be useful to help to predict long-term atmospheric corrosion of CS and ASTM A-242 WS [92]. No differences are seen within the rural-urban-industrial group in the value of $n$ for each of these types of atmospheres, nor in the atmospheres of a marine nature, whether or not they were close to the shoreline. The latter again confirms the high significance of the marine character of the atmosphere (which does not distinguish between the various chloride levels) in exponent $n$ seen in a prior statistical study [93]. Attention is also drawn to the $65-70 \%$ drop in the value of $n$ for WS compared to CS in any atmosphere.

A study of WS by Coburn et al. [41] which considered two different angles of exposure $\left(30^{\circ}\right.$ and $90^{\circ}$ ) and orientations (facing south and facing north) did not show any great effect of either variable on the exponent $n$ value of the Eq. (2). The value of $n$ only acquired slightly higher values on the specimens exposed at a $90^{\circ}$ slope and oriented facing north. 
With regard to the effect of sheltering on exponent $n$ in Eq. (2) for WS, on the basis of 8-year data observed in the UN/ECE exposure programme [26] in a set of 36 testing stations corresponding to 14 countries, Fig. 14 points to an important effect whereby exponent $n$ takes on significantly higher values in sheltered exposure than in unsheltered exposure. In a publication by Tidblad et al. [94] based on data obtained in this same UN/ECE programme, the authors note that $n$ changes drastically from about 0.5 for shorter exposure times (1-2 years) to less than 0.2 after 8 years of exposure for unsheltered samples, which practically means that the corrosion products are almost completely protective. In sheltered position the exponent $n$ changes from about 1.0 to 0.5 during the same period.

\subsubsection{Numerical power model}

There are examples in the literature $[40,95]$ of data that does not fully fit Eq. (2). After a certain exposure time in which this function is indeed followed, the results diverge from the predicted behaviour and are fitted by another straight line whose slope is shallower than the first (Fig. 15). The bi-linear graph obtained on log-log coordinates instead obey an equation of the following type:

$$
C=C_{1} t_{p}{ }^{n_{1}-n_{2}} t^{n_{2}} \quad\left(t \geq t_{p}\right)
$$

where $C$ is the corrosion after $\mathrm{t}$ years, $C_{1}$ is the first year corrosion, $t_{p}$ is the duration (in years) of the first exposure period whose slope is $n_{1}$, and $n_{2}$ is the slope of the second period. One possible reason for this singular behaviour may lie in the formation with time of more compact rust layers which impede the diffusion of the reactive species that participate in the corrosion reactions.

McCuen et al. [48] proposed to improve the power model by numerically fitting coefficients $A$ and $n$ with the non-linear least-squares method directly to the actual values of variables $C$ and $t$, not the logarithms of the variables, since the logarithmic transformation lends too much weight to the penetration data for shorter exposure. This eliminates the overall bias, and more accurately predicts penetration for longer exposure times. They refer to this new model as the numerical power model, which has the same functional form as the bilogarithmic model.

In order to know what law best predicts the atmospheric corrosion of WS, it is necessary to refer to a greater volume of information that makes reference to exposure times of $>10-20$ years. In this respect, McCuen et al. [48] consider that penetration data for exposure times of at least ten years is needed to reliably estimate the penetration at the end of a 50-100 year service life, in contrast to the opinion of Pourbaix [49], who stated that 1 to 4 years exposure data was sufficient to make long-term forecasts (20-30 years).

\subsection{3. $\quad$ Power- linear model}

McCuen et al. [48] saw that WS corrosion penetration data revealed behaviour differences that could not all be explained by the parabolic model and thus preferred a composite model (power-linear model) consisting of a power function for short exposure times, up to 3 to 5 years, followed by a linear function for longer exposure times. This model is similar to that used to develop standard ISO 9224 [96], which envisages two exposure periods with different corrosion kinetics. In the first period, covering the first ten years of exposure, the growth law is 
parabolic (average corrosion rate, $\mathrm{r}_{\mathrm{av}}$ ), while in second period, for times of more than 10 years, the behaviour is linear (steady-state corrosion rate, $r_{\text {lin }}$ ).

ISO 9224 offers information on guiding corrosion values for CS and WS in each time period according to the atmospheric corrosivity as defined in ISO 9223 [57]. The guiding corrosion values are based on experience obtained with a large number of exposure sites and service performances.

The question of whether this law provides a better prediction of WS corrosion cannot be fully answered until a greater volume of data is available for analysis, with reference to exposure times of at least 20 years. McCuen and Albrecht compared both models (the power model and the power - linear model) using atmospheric corrosion data reported for WS in the United States and concluded that the experimental data fitted the power-linear model better than the power model and thus provided more accurate predictions of long-term atmospheric corrosion [48]. The improvement in accuracy was greatest for plain carbon steel and copper steel data, and less for ASTM A-588 and A-242 steel data.

\subsection{4. $\quad$ Bi-linear model}

Some refinement of the power-linear model has been reported for Albrecht and Hall [7], where the authors proposed a new bi-linear model based on ISO 9224, called modified ISO 9224 (Fig. 16a), as well as an adjustment of this new bi-linear model that accounts for a modified corrosion rate during the first year of exposure and a steady state during subsequent years. An application of this adjustment for the upper and lower curves in the medium corrosivity category C3 is reported in Figure 16b.

\subsection{Damage (dose-response) functions}

Different models have recently been developed with the aim of generalising the corrosion loss over time for different environments, reporting climate and pollutant variables as independent factors. Two of these models are presented below.

Several dose-response functions have been developed within the International Cooperative Programme (ICP) on "Effects on Materials, including Historic and Cultural Monuments" in the framework of the UN/ECE convention on long range transboundary air pollution [97]. These functions have been formulated for WS (Table 10) and are based on both long-term exposures and trend analysis based on repeated one-year measurements, also taking into account unsheltered or sheltered exposure. The degradation of WS over time is expressed by means of mass loss $(\mathrm{ML})$ as a function of climatic parameters $(\mathrm{Rh}, \mathrm{T})$ and $\mathrm{SO}_{2}$ concentration as reported in Table 10. Further details can be found in reference [97].

Finally, Klinesmith et al. [98] mention that all variation related to environmental conditions appears as error variation in the time-dependent models for models that predict corrosion loss as a function of time only. Furthermore, time-dependent models will yield inaccurate predictions when used to estimate corrosion loss in environments that are different from the environment where the model was calibrated. To overcome this problem, a model is proposed that incorporates multiple environmental factors such as time of wetness (TOW), sulphur dioxide $\left(\mathrm{SO}_{2}\right)$, chloride content $\left(\mathrm{Cl}^{-}\right)$and temperature $(\mathrm{T})$ : 


$$
C=A t^{B}\left(\frac{T O W}{D}\right)^{E}\left(1+\frac{S O_{2}}{F}\right)^{G}\left(1+\frac{C l}{H}\right)^{\prime} e^{J_{(T+T O)}}
$$

where $A, B, D, E, F, G, H, I, J$ and $T_{0}$ are empirical coefficients.

The model was formulated for different metals and the results indicate that it was reliable for use in a broad range of conditions or locations.

According to Landolfo et al. [99], as far as Klinesmith's corrosion model is concerned, the thickness loss values predicted for one year exposure are very close to EN 12500 [100], but in the long-term the model provides an average thickness loss of about $1.7 \mathrm{~mm}$ for a design life of 50 years, which is approximately 10-times more than the forecasts given by the other models.

In order to evaluate the differences between several corrosion models and corrosion rates for WS, Landolfo et al. have undertaken a comparison [99]. Good agreement between the selected corrosion models and corrosion rates can be observed in the case of WS for both short- and long -term exposures.

Despite mentioned inconvenients, recent studies on the long-term atmospheric corrosion of WS continue to use the power function $\left(C=A t^{n}\right)$ because of its simplicity $[86,101]$, although ignoring the linear part (parabolic-linear model) will introduce considerable error in thickness estimates for long exposure times.

\section{Conclusions}

The following conclusions can be drawn from the in-depth bibliographic review of information on the atmospheric corrosion data of conventional WS:

a) The rust layer stabilisation (consolidation) time decreases as the corrosivity of the exposure atmosphere rises, dropping from 6-8 years in less corrosive atmospheres (C2C3) to 4-6 years in more corrosive atmospheres (C3-C5).

b) The steady-state corrosion rate of WS increases with the corrosivity of the atmosphere. The use of unpainted WS (corrosion rate $\leq 6 \mu \mathrm{m} / \mathrm{year}$ ) is restricted to non-marine atmospheres with low corrosivity, C2-C3 (low).

c) The exposure geometry (angle of exposure, orientation) influences WS corrosion although its impact is only moderate. In contrast, the presence of atmospheric pollutants $\mathrm{SO}_{2}$ in urban and industrial atmospheres and $\mathrm{Cl}^{-}$in marine atmospheres have a rather considerable effect on WS corrosion. There seem to be a critical $\mathrm{SO}_{2}$ level of close to $20 \mathrm{mg} \mathrm{SO} / \mathrm{m}^{2} . \mathrm{d}$ and a critical $\mathrm{Cl}^{-}$level of around $3 \mathrm{mg} / \mathrm{m}^{2}$.d above which the application of unpainted conventional WS is not feasible.

d) With regard to the effect of sheltered exposure, in atmospheres of low corrosivity (C2C3) practically no effect is seen, but when the corrosivity category approaches C4, sheltered exposure accelerates the WS corrosion rate.

e) Continuously moist exposure does not allow the formation of protective rust layers due to the lack of the necessary wet/dry cycles. Furthermore, as in indoor exposure, WS corrosion is not so different to that experienced by CS, and thus the use of WS is not justified. 
f) It is very common to use a power function $\left(C=A t^{n}\right)$, or its logarithmic transformation $(\log C=\log A+n \log t)$, to predict the long-term atmospheric corrosion of WS. $n$ values for WS, which are in average 33\% lower than for CS, are higher in marine atmospheres $(n=0.5)$ than in other types of atmospheres (rural-urban-industrial) $(n=0.3)$. 


\section{References}

[1] T. Murata, Weathering steel, in: R.W. Revie (Ed.), Uhlig's Corrosion Handbook, J. Wiley \& Sons, New York, 2000.

[2] ASTM A-242 / A-242M-04, Standard specification for high-strength low-alloy structural steel, American Society for Testing and Materials, Philadelphia, 2007.

[3] ASTM A709 /A709M, Standard specification for structural steel for bridges, American Society for Testing and Materials, Philadelphia, 2009.

[4] A-588 / A-588M, Standard specification for high-strength low alloy structural steel with $50 \mathrm{ksi}$ [345 MPa] minimum yield point to 4-in. [100 mm] thick, American Society for Testing and Materials, Philadelphia, 2005.

[5] V. Kucera, E. Mattsson, Atmospheric corrosion, in: F. Mansfeld (Ed.), Corrosion Mechanisms, Marcel Dekker, New York, 1987, pp. 211-284.

[6] C. Leygraf, T. Graedel, Atmospheric Corrosion, Electrochemical Society Series, J. Wiley \& Sons, New York, USA, 2000.

[7] P. Albrecht, T.T. Hall, Atmospheric corrosion resistance of structural steels, J. Mater. Civil Eng. 15 (2003) 2-24.

[8] F.B. Fletcher, Corrosion of weathering steels, in: Vol 13B: Corrosion: Materials, ASM Handbook, 2005, pp. 28-34.

[9] D.M. Buck, Copper in steel - The influence on corrosion, J. Ind. Eng. Chem. 5 (1913) 447-452.

[10] D.M. Buck, Recent progress in corrosion resistance, Iron Age (1915) 1231-1239.

[11] G. Smith, Steels fit for the countryside, New Scientist (1971) 211-213.

[12] C.P. Larrabee, S.K. Coburn, The atmospheric corrosion of steels as influenced by changes in chemical composition, First International Congress on Metallic Corrosion, London, 1961, pp. 279-285.

[13] W.K. Boyd, Corrosion of metals in the atmosphere, in: Metals and Ceramics Information Center, Columbus, 1974, pp. 1-18.

[14] H.R. Copson, Long-time atmospheric corrosion tests on low-alloy steels, Proceedings ASTM 60, 1960, pp. 1-16.

[15] Material Specification 531, Weathering fine grain structural steel, COR-TEN A, ThyssenKrupp Steel Europe, March 2007.

[16] Material Specification 532, Weathering fine grain structural steel, COR-TEN B, ThyssenKrupp Steel Europe, August 2005.

[17] A. Azizinamini, High- Performance Steel: New Horizon in Steel Bridge Construction, Transportation Research Board, Washington, D.C., 1998.

[18] A.D. Wilson, Properties of recent production of A709 HPS 70W bridge steels, in: International Symposium on Steel for Fabricated Structures, ASM International, Cincinnati, 1999, pp. 41-49.

[19] R.J. Schmitt, W.P Gallagher, Unpainted high strength low alloy steel, Materials Protection 8 (1969) 70-77. 
[20] I. Matsushima, Y. Ishizu, T. Ueno, M. Kanasashi, K. Horikawa, Effect of structural and environmental factors on the practical use of low-alloy weathering steel, Corrosion Engineering 23 (1974) 177-182.

[21] S. Feliu, M. Morcillo, Corrosión y Protección de los Metales en la Atmósfera, Bellaterra, Barcelona, 1982.

[22] A. Bragard, H. Bonnarens, Atmospheric conditions and durability of weathering steels, C.R.M. Report N. 57, December, 1980.

[23] A.A. Bragard, H.E. Bonnarens, Prediction at long terms of the atmospheric corrosion of structural steels from short-term experimental data, in: S.W. Dean Jr., E.C. Rhea (Eds.), Atmospheric Corrosion of Metals, ASTM STP 767, American Society for Testing and Materials, 1982, pp. 339-358.

[24] R. de O. Vianna, M.F. Cunha, A.C. Dutra, Comparative behavior of carbon steel and weathering stels exposed for five years to different climates in Brazil, Proceedings 9th International Congress on Metalic Corrosion, Toronto, Vol. 3, National Research Council, Ed, 1984, pp. 211-215.

[25] A.C. Dutra, R. de O. Vianna, Atmospheric corrosion testing in Brazil, in: W.H. Ailor (Ed.), Atmospheric Corrosion, The Electrochemical Society, John Wiley and Sons, New York, 1982, pp. 755-774.

[26] UN/ECE International Cooperative Programme on Effects on Materials including Historic and Cultural Monuments, Report N. 22: Corrosion attack on weathering steel, zinc and aluminium. Evaluation after 8 years of exposure, SVUOM, Prague, May 1998.

[27] W. Hou, Atmospheric corrosion of steels, Proceedings $11^{\text {th }}$ International Congress on Metallic Corrosion, Firenze, 1990, pp. 2.55-2.61.

[28] W. Hou, C. Liang, Eight-year atmospheric corrosion exposure of steels in China, Corrosion 55 (1999) 65-73.

[29] W.T. Hou, C.F. Liang, Effects of alloying on atmospheric corrosion of steels, in: H.E. Townsend (Ed.), Outdoor Atmospheric Corrosion, ASTM STP 1421, American Society for Testing and Materials, West Conshohocken, 2002, pp. 368-377.

[30] W. Hou, C. Liang, Atmospheric corrosion prediction of steels, Corrosion 60 (2004) 313322.

[31] D. Knotkova, L. Rozlivka, J. Vlckova, Corrosion properties of weathering steels, Proceedings of $8^{\text {th }}$ International Congress on Metallic Corrosion, Frankfurt / Main, Vol. II, 1981, pp. 1792-1799.

[32] D. Knotkova, J. Vlckova, J. Honzak, Atmospheric corrosion of weathering steels, in: S.W. Dean Jr., E.C. Rhea (Eds.), Atmospheric Corrosion of Metals, ASTM STP 767, American Society for Testing and Materials, 1982, pp. 7-44.

[33] D. Knotkova, K. Barton, M. Cerny, Atmospheric corrosion testing in Czechoslovakia, in: W.H. Ailor(Ed.), Atmospheric Corrosion, The Electrochemical Society, John Wiley and Sons, New York, 1982, pp. 991-1014.

[34] G. Burgmann, D. Grimme, Investigations into the atmospheric corrosion of plain carbon and low-alloy steels at various environmnetal conditions, Stahl Eisen 100 (1980) 641-650.

[35] K. Bohnenkamp, G. Burgmann, W. Schwenk, Corrosion atmospherique de l'acier doux. Exposition de l'acier aux intemperies, Galvano-Organo 445 (1974) 587-589. 
[36] T. Moroishi, J. Satake, Effect of alloying elements on atmospheric corrosion of hightensile strength steels, Transactions of the Iron and Steel Institute of Japan 13 (1973) 165-165.

[37] T. Fukushima, N. Satu, Y. Hisamatsu, J. Matsushima, Y. Aoyama, Atmospheric corrosion testing in Japan, in: W.H. Ailor (Ed.), Atmospheric Corrosion, The Electrochemical Society, John Wiley and Sons, New York, 1982, pp. 841-872.

[38] C.R. Southwell, J.D. Bultman, A.L. Alexander, Corrosion of metals in tropical environments - Final report of 16-year exposures, Mater. Performance 15 (1976) 9-26.

[39] F.I. Wei, Atmospheric corrosion of carbon steels and weathering steels in Taiwan, $\mathrm{Br}$. Corros. J. 26 (1991) 209-214.

[40] J.H. Wang, F.I. Wei, Y.S. Chang, H.C. Shih, The corrosion mechanisms of carbon steel and weathering steel in $\mathrm{SO}_{2}$ polluted atmospheres, Mater. Chem. Phys. 47 (1997) 1-8.

[41] S.K. Coburn, M.E. Komp, S.C. Lore, Atmospheric corrosion rates of weathering steels at test sites in the eastern United States. Effect of environment and test panel orientation, in: W.W. Kirk, H.H. Lawson (Eds.), Atmospheric Corrosion, ASTM STP 1239, American Society for Testing and Materials, Philadelphia, 1995, pp. 101-113.

[42] H.E. Townsend, J. Zoccola, Eight-year atmospheric corrosion performance of weathering steel in industrial, rural and marine environments, in: S.W. Dean Jr., E.C. Rhea (Eds.), Atmospheric Corrosion of Metals, ASTM STP 767, American Society for Testing and Materials, 1982, pp. 45-59.

[43] C.R. Shastry, J.J. Friel, H.E. Townsend, Sixteen-year atmospheric corrosion performance of weathering steels in marine, rural and industrial environments, in: S.W. Dean, T.S. Lee (Eds.), Degradation of Metals in the Atmosphere, ASTM STP 965, American Society of Testing and Materials, Philadelphia, 1988, pp. 5-15.

[44] F.H. Haynie, J.B. Upham, Effects of atmospheric pollutants on corrosion behavior of steels, Materials Protection and Performance 10 (1971) 18-21.

[45] G.B. Mannweiler, Corrosion test results of fifteen ferrous metals after seven-years atmospheric exposure, in: Metal Corrosion in the Atmosphere, ASTM STP 435, American Society for Testing and Materials, 1968, pp. 211-222.

[46] H.R. Copson, Atmospheric corrosion of low alloy steels, Proceedings ASTM 52 (1952) 1005-1026.

[47] J.B. Horton, The composition, structure and growth of the atmospheric rust on various steels, Ph. Thesis, Lehigh University, Bethlehem, 1964.

[48] R.H. McCuen, P. Albrecht, J.G. Cheng, A new approach to power-model regression of corrosion penetration data, in: V. Chaker (Ed.), Corrosion Forms and Control for Infrastructure, ASTM STP 1137, American Society for Testing and Materials, Philadelphia, 1992, pp. 46-76.

[49] M. Pourbaix, The linear bilogaritmic law for atmospheric corrosion, in: W.H. Ailor (Ed.), Atmospheric Corrosion, The Electrochemical Society, John Wiley and Sons, New York, 1982, pp. 107-121.

[50] R.A. Legault, A.G. Preban, Kinetics of atmospheric corrosion of low-alloy steels in an industrial environment, Corrosion (NACE) 31 (1975) 117-122.

[51] Ch. Cao, Some results of long-term atmospheric exposure tests of steels in China, $16^{\text {th }}$ International Corrosion Congress, Chinese Society for Corrosion and Protection, Beijing, 2005. 
[52] C. Liang, W. Hou, Sixteen year atmospheric corrosion exposure study of steels, $16^{\text {th }}$ International Corrosion Congress, Chinese Society for Corrosion and Protection, Beijing, 2005.

[53] H.E. Townsend, Atmospheric corrosion performance of quenched-and-tempered, highstrength weathering steel, Corrosion (NACE) 56 (2000) 883-886.

[54] L. Damian, R. Fako, Weathering structural steels corrosion in atmospheres of various degrees of pollution in Romania, Mater. Corros. 51 (2000) 574-578.

[55] A.U. Leuenberger-Minger, B. Buchmann, M. Faller, P. Richner, M. Zobeli, Doseresponse functions for weathering steel, copper and zinc obtained from a four-year exposure programme in Switzerland, Corros. Sci. 44 (2002) 675-687.

[56] I. Díaz, H. Cano, B. Chico, D. De la Fuente, M. Morcillo, Some clarifications regarding literature on atmospheric corrosion of weathering steels, International Journal of Corrosion, ID 812192 (2012) 1-9.

[57] ISO 9223, Corrosion of metals and alloys. Clasiffication of corrosivity of atmospheres, International Standard Organization, Geneve, 1991.

[58] D.C. Cook, An active coating and new protection technology for weathering steel structures in chloride containing environments, NACE International, Nashville, Tennessee (USA), 2007.

[59] H. Kihira, M. Kimura, Advancements of weathering steel technologies in Japan, Corrosion 67 (2011) 1-13.

[60] Technical Report: Guideline for designing and construction of bridges by weathering steel, Kozai Club (Ed.), Tokyo, 1993.

[61] Specification for highway bridges, Japan Road Association, Tokio, 2002.

[62] D.C. Cook, The corrosion of high performance steel in adverse environments, ISIAME, Madrid, 2004, pp. 63-72.

[63] D.C. Cook, Spectroscopic identification of protective and non-protective corrosion coatings on steel structures in marine environments, Corros. Sci. 47 (2005) 2550-2570.

[64] K. Park, Corrosion resistance of weathering steels, Ph. Thesis, Department of Civil and Environmental Engineering, University of Maryland, USA, 2004.

[65] J. Gullman et al., Corrosion resistance of weathering steels - typical causes of damage in building context and their prevention, Bull. 94, Swedish Corrosion Institute, Stockholm, 1985.

[66] C.P. Larrabee, The effect of specimen position on atmospheric corrosion testing of steel, Trans. Electrochem. Soc. 85 (1944) 297-306.

[67] G. Schikorr, The atmospheric oxidisation of Iron II, Zeitschrift fur Elektrochemie und Angewandte Physikalische Chemie 43 (1937) 697-704.

[68] ASTM G50, Conducting atmospheric corrosion tests on metals, American Society for Testing and Materials, Philadelphia, 1991.

[69] F.L. LaQue, Corrosion testing, Proceedings ASTM 51 (1951) 495-582.

[70] C.P. Larrabee, Corrosion resistance of high-strength low-alloy steels as influenced by composition and environment, Corrosion (NACE) 9 (1953) 259-271. 
[71] B. Cosaboom, G. Mehalchick, J. Zoccola, Bridge construction with unpainted hightrength low-alloy steel: eight-year progress report, New Yersey Department of Transportation, New Yersey, 1979.

[72] J. Zoccola, A.J. Permoda, L.T. Oehler, J.B. Horton, Performance of Mayari R weathering steel (ASTM A242) in bridges, eight-mile road over John Lodge expressway, Detroit, Michigan, Bethlehem Steel Corporation, 1970.

[73] J. Zoccola, Eight year corrosion test report - Eight mile road interchange, Bethlehem Steel, Bethlehem, 1976.

[74] S. Oesch, P. Heimgartner, Environmental effects on metallic materials - Results of an outdoor exposure programme running in Switzerland, Mater. Corros. 47 (1996) 425438.

[75] T. Moroishi, J. Satake, The influence of the inclination and direction of specimen surface on atmospheric corrosion of steels, Tetsu - to - Hagane 59 (1) (1973) 125-130.

[76] J. Satake, T. Moroishi, Y. Nishida, S. Tanaka, Sumitomo Metals 22 (4) (1970) 516-520. (in Japanese)

[77] M. McKenzie, The corrosion performance of weathering steel in highway bridges, in: W.H. Ailor (Ed.), Atmospheric Corrosion, The Electrochemical Society, John Wiley and Sons, New York, 1982, pp. 717-736.

[78] National Academy of Sciences, An analysis of atmospheric corrosion tests in low-alloy steels - Applicability of test results to highway bridges, Highway Research Record, No. 204, Nat. Acad. Sci., Washington DC., 1967.

[79] J.M. Costa, M. Morcillo, S. Feliu, Effect of environmental parameters on atmospheric corrosion of metals, in: P.N. Cheremisinoff (Ed.), Encyclopedia of Environmental Control Technology: Air Pollution Control, Gulf Publishing Company, Houston, 1989, pp. 197-238.

[80] D.D.N. Singh, S. Yadav, J.K. Saha, Role of climatic conditions on corrosion characteristics of structural steels, Corros. Sci. 50 (2008) 93-110.

[81] J. Satake, T. Moroishi, Various factors affecting atmospheric corrosion of steels, $5^{\text {th }}$ International Congress on Metallic Corrosion, Tokyo, Japan, 1972, pp. 744-749.

[82] D.M. Murray, Economic analysis of the environmental impact of highway deicing salts, Transportation Research Record 647, Transportation Research Board, Washington, D.C, 1977.

[83] A. Naeemi, P. Albrecht, Atmospheric corrosion of weathering steels, Proceedings of 9th International Congress of Metallic Corrosion, Toronto, Vol. 1, National Research Council, Ed, 1984, pp. 418-427.

[84] W. Hein, S. Sczyslo, Corrosion behaviour of weathering steels under deicing salt exposure, Interim Report no 4, Bundesanstalt Fuer Wasserbaw, Federal Republic of Germany, 1981.

[85] ASTM G 101-04, Standard guide for estimating the atmospheric corrosion resistance of low-alloy steels, American Society for Testing and Materials, Philadelphia, 2004.

[86] H.E. Townsend, The effects of alloying elements on the corrosion of steel in industrial atmospheres, Proceedings 14th International Corrosion Congress, Cape Town, Corrosion Institute of Southern Africa, 1999. 
[87] H.E. Townsend, Estimating the atmospheric corrosion resistance of weathering steels, in: H.E. Townsend (Ed), Outdoor Atmospheric Corrosion, ASTM STP 1421, American Society for Testing and Materials, PA, USA, 2002, pp. 292-300.

[88] K. Bohnenkamp, G. Burgmann, W. Schwenk, Investigations of atmospheric corrosion of plain carbon and low-alloy steels in industry, country and sea air, Stahl Eisen 93 (1973) 1054-1060.

[89] S. Feliu, M. Morcillo, Atmospheric corrosion testing in Spain, in: W.H. Ailor (Ed.), Atmospheric Corrosion, J. Wiley \& Sons, New York, 1982, pp. 913-922.

[90] M. Benarie, F.L. Lipfert, A general corrosion function in terms of atmospheric pollutant concentrations and rain pH, Atmos. Environ. 20 (1986) 1947-1958.

[91] R.A. Legault, V.P. Pearson, Atmospheric corrosion in marine environments, Corrosion (NACE) 34 (1978) 433-437.

[92] M. Morcillo, J. Simancas, S. Feliu, Long-term atmospheric corrosion in Spain: results after 13 to 16 years of exposure and comparison with worldwide data, in: W.W. Kirk, H.H. Lawson (Ed.), Atmospheric Corrosion, ASTM STP 1239, American Society for Testing and Materials, Philadelphia, 1995, pp. 195-214.

[93] S. Feliu, M. Morcillo, S. Feliu Jr, The prediction of atmospheric corrosion from meteorological and pollution parameters.2. Long-term forecasts, Corros. Sci. 34 (1993) 415-422.

[94] J. Tidblad, J.K. Kreislova, D. Knotkova, V. Kucera, Exposure of weathering steel in the UN/ECE ICP Materials Programme, International Workshop on Atmospheric Corrosion and Weathering Steels, Cartagena de Indias, 2004.

[95] M. Morcillo, S. Feliu, J. Simancas, Deviation from bilogarithmic law for atmospheric corrosion of steel, Br. Corros. J. 28 (1993) 50-52.

[96] ISO 9224, Corrosion of metals and alloys - Corrosivity of atmospheres - Guiding values for the corrosivity categories, International Standards Organization, Geneve, 1992.

[97] V. Kucera, Mapping Effects on Materials in Manual Mapping Critical Load, ICP Materials, Coordination Centre: Stockholm, 2004. Available online: http://icpmapping.org.

[98] D.E. Klinesmith, R.H. McCuen, P. Albrecht, Effect of environmental conditions on corrosion rates, J. Mater. Civil Eng. 19 (2007) 121-129.

[99] R. Landolfo, L. Cascini, F. Portioli, Modeling of metal structure corrosion damage: A state of the art report, Sustainability 2 (2010) 2163-2175.

[100] EN 12500, Corrosion likelihood in atmospheric environment, European Committee for Standardization (CEN), Brussels, 2000.

[101] S.W. Dean, D. Knotkova, J.K. Kreislova, ISOCORRAG International Atmospheric Exposure Program: Summary of Results, ASTM Series 71, ASTM International, West Conshohocken, 2010. 


\section{FIGURE CAPTIONS}

Figure 1. Atmospheric corrosion of Cor-Ten B steel and its evolution with exposure time in the industrial atmosphere of Kearny [12]. Comparison with Cu-bearing steel and plain carbon steel (CS).

Figure 2. Determination of rust layer stabilisation time and steady-state corrosion rate from a plot of exponential decrease function obtained with corrosion rate data at different exposure times.

Figure 3. Box-whisker plots of rust layer stabilisation time of weathering steel as a function of atmospheric corrosivity category (ISO 9223 [57]).

Figure 4. Box-whisker plots of weathering steel steady-state corrosion rate as a function of atmospheric corrosivity category (ISO 9223 [57]). Non-marine (rural-urbanindustrial) atmospheres.

Figure 5. Box-whisker plots of weathering steel steady-state corrosion rate as a function of atmospheric corrosivity category (ISO 9223 [57]). Marine atmospheres.

Figure 6. Typical plots of corrosion versus exposure time for weathering steels (ASTM A-242 (a), due to Schmitt and Gallagher [19], and ASTM A-588 (b), due to Townsend and Zoccola [42] and Shastry, Friel and Townsend [43]) in different types of atmospheres.

Figure 7. Corrosion versus exposure time for weathering steel (WS) and reference plain carbon steel (CS) in atmospheres with different $\mathrm{SO}_{2}$ content. Plots have been elaborated from graphs showed in reference [32].

Figure 8. Corrosion of weathering steel in outdoor atmospheres as a function of $\mathrm{SO}_{2}$ pollution level [32].

Figure 9. Variation of atmospheric corrosion rate of conventional weathering steel with atmospheric $\mathrm{SO}_{2}$ content. Constructed from data corresponding to 8-year exposure, provided by UNECE/PIC Materials [26].

Figure 10. Influence of airborne salts (atmospheric salinity) on corrosion rate of conventional weathering steel. The figure has been obtained from references [60] and [62].

Figure 11. Typical log-log plots of weathering steel corrosion versus exposure time at different test sites.

Figure 12. Log-log plots of weathering steel corrosion versus exposure time in data series not well adapted to the power function $\left(C=A t^{n}\right)$, with low correlation coefficients $(\rho)$.

Figure 13. Box-whisker plots of $n$ values in power function $\left(C=A t^{n}\right)$ for different types of atmospheres.

Figure 14. Box-whisker plots of $n$ values in power function $\left(C=A t^{n}\right)$ for sheltered and unsheltered exposures.

Figure 15. Bi-linear log-log plots of weathering steel corrosion versus exposure time for data series not well adapted to the power function $\left(C=A t^{n}\right)[95]$. 
Figure 16. Bi-linear plots of weathering steel corrosion versus exposure time [7]: (a) Modified ISO 9224 for different ISO 9223 [57] corrosivity categories; (b) Albrecht et al. adjustment and modified ISO 9224 for C3 corrosivity category. 


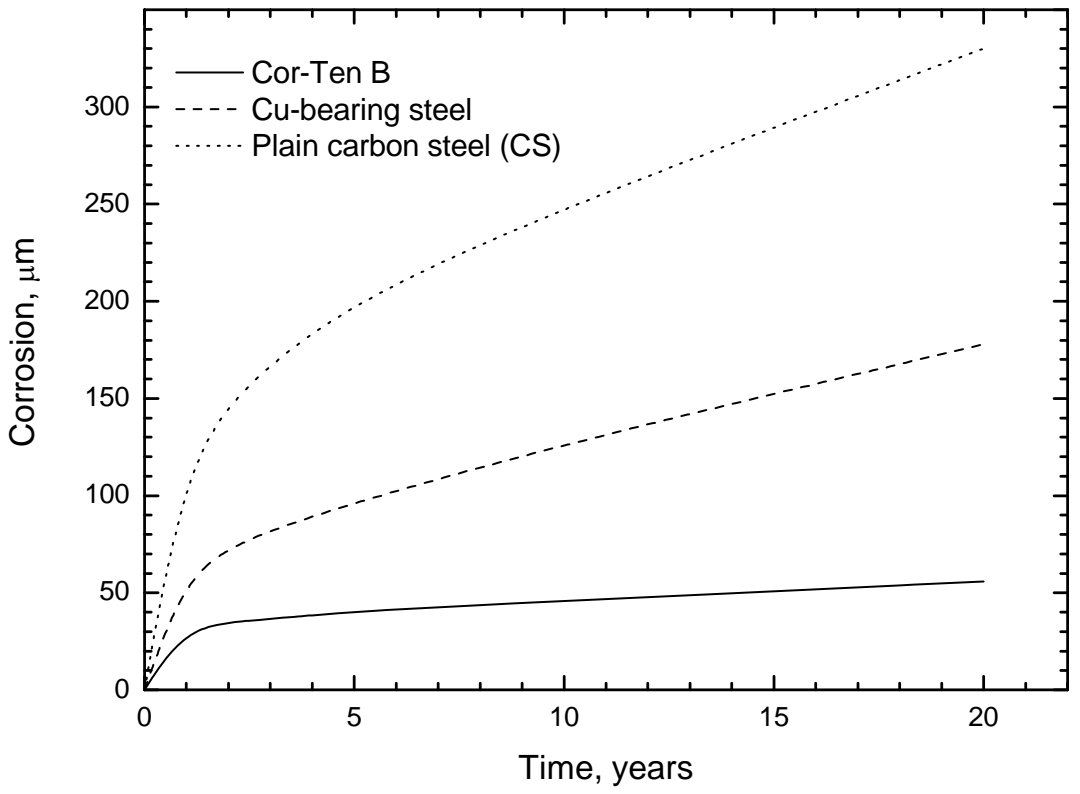

Figure 1. 


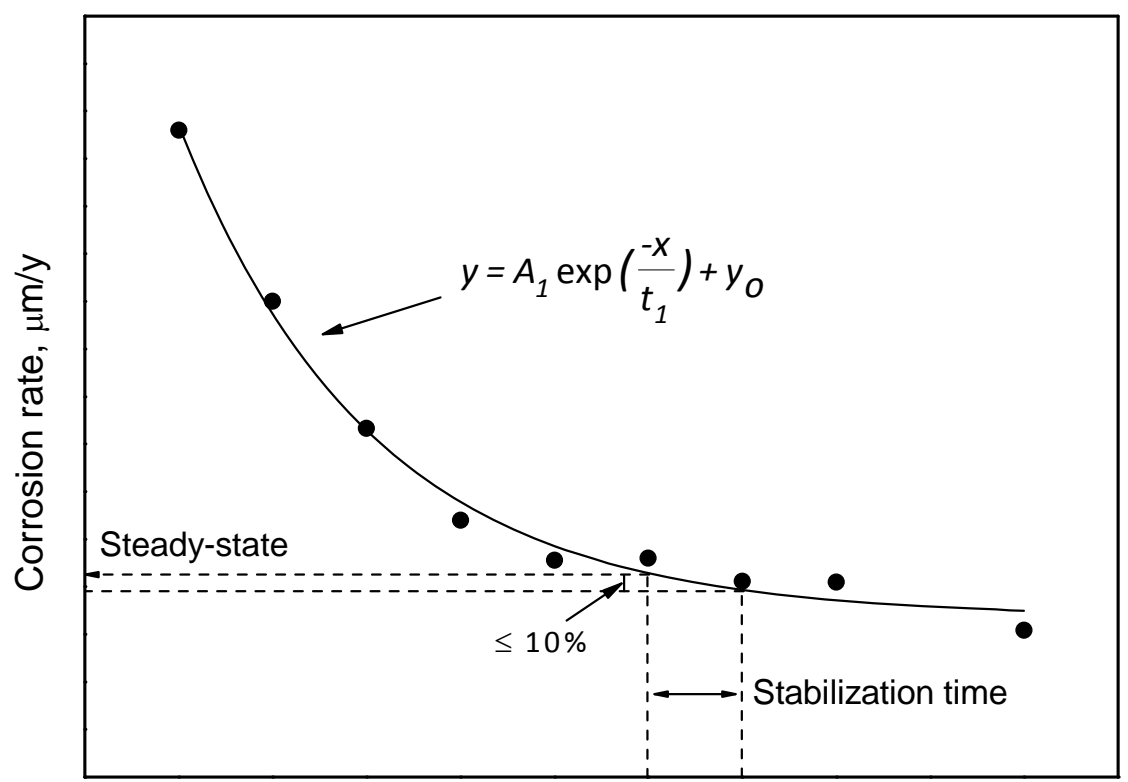

Time, years

Figure 2 


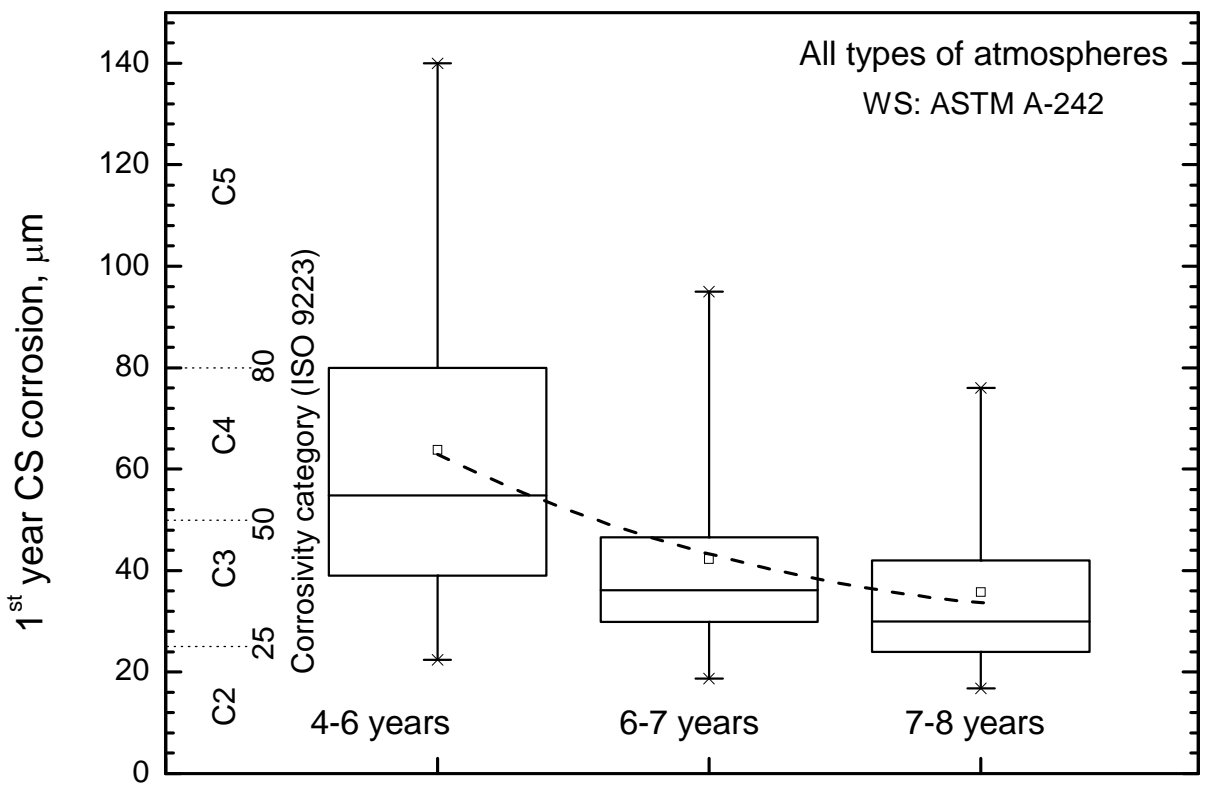

Stabilization time, years

Figure 3 


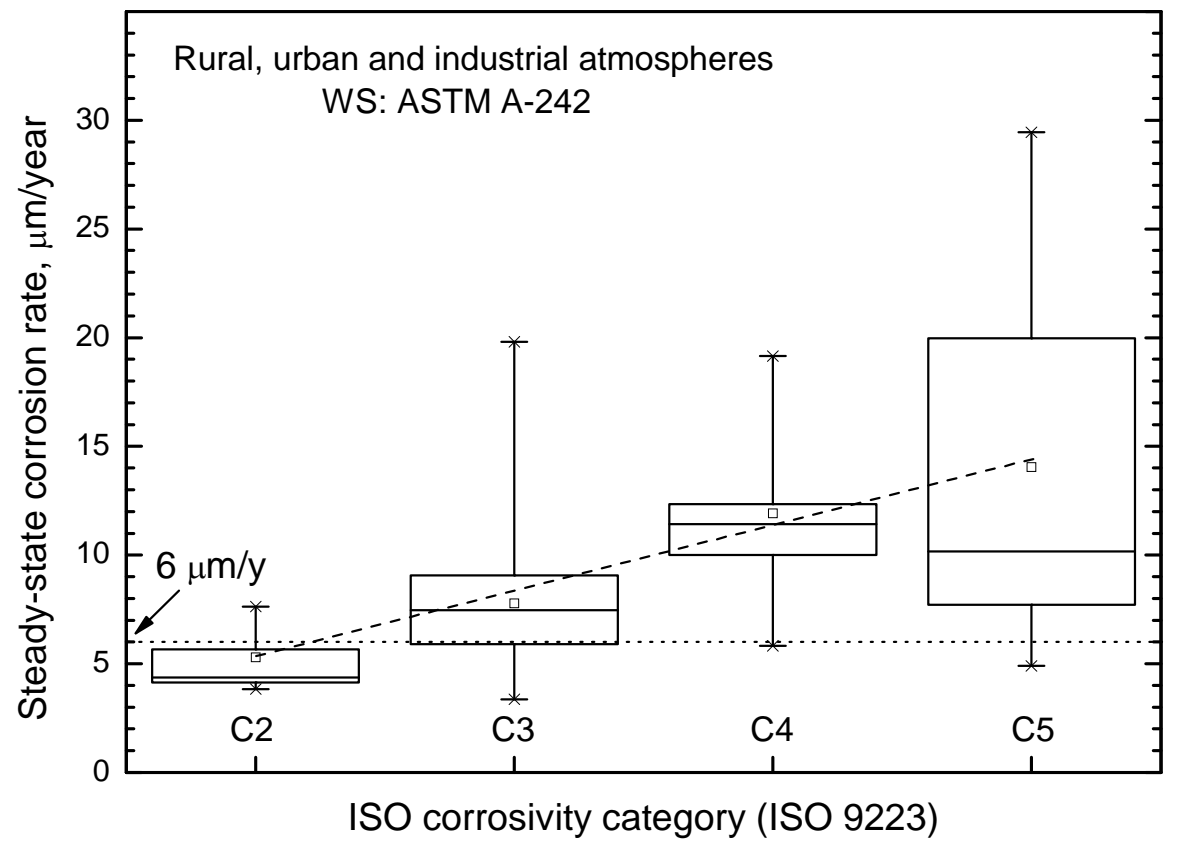

Figure 4 


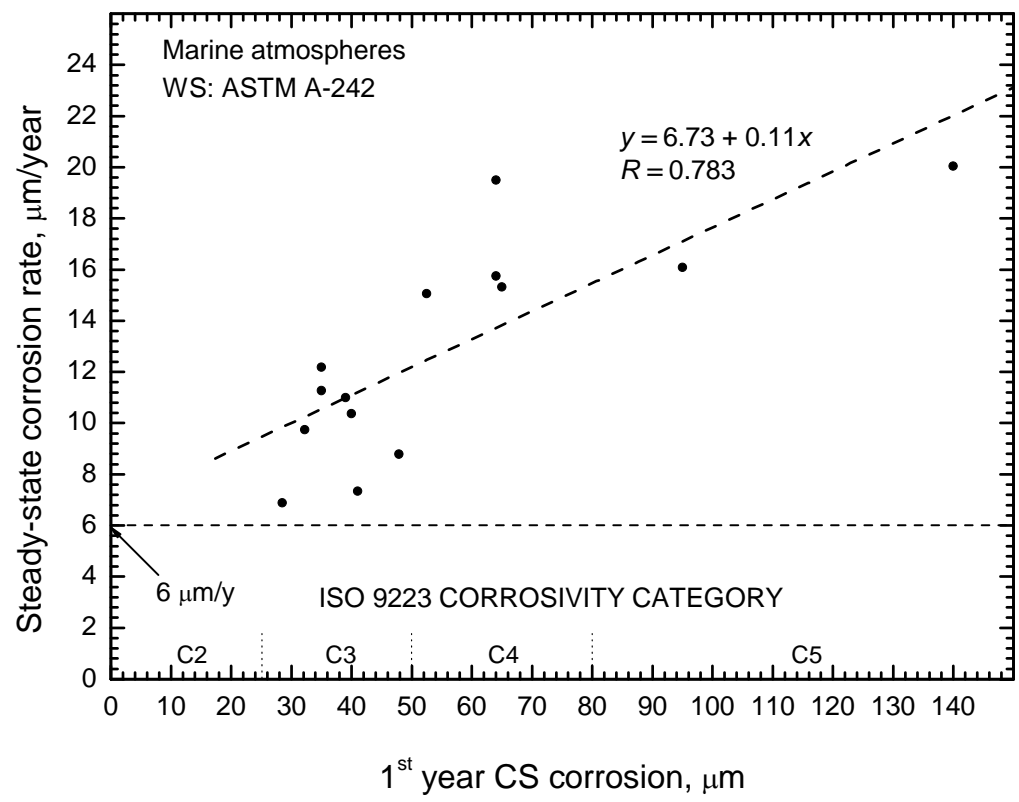

Figure 5 

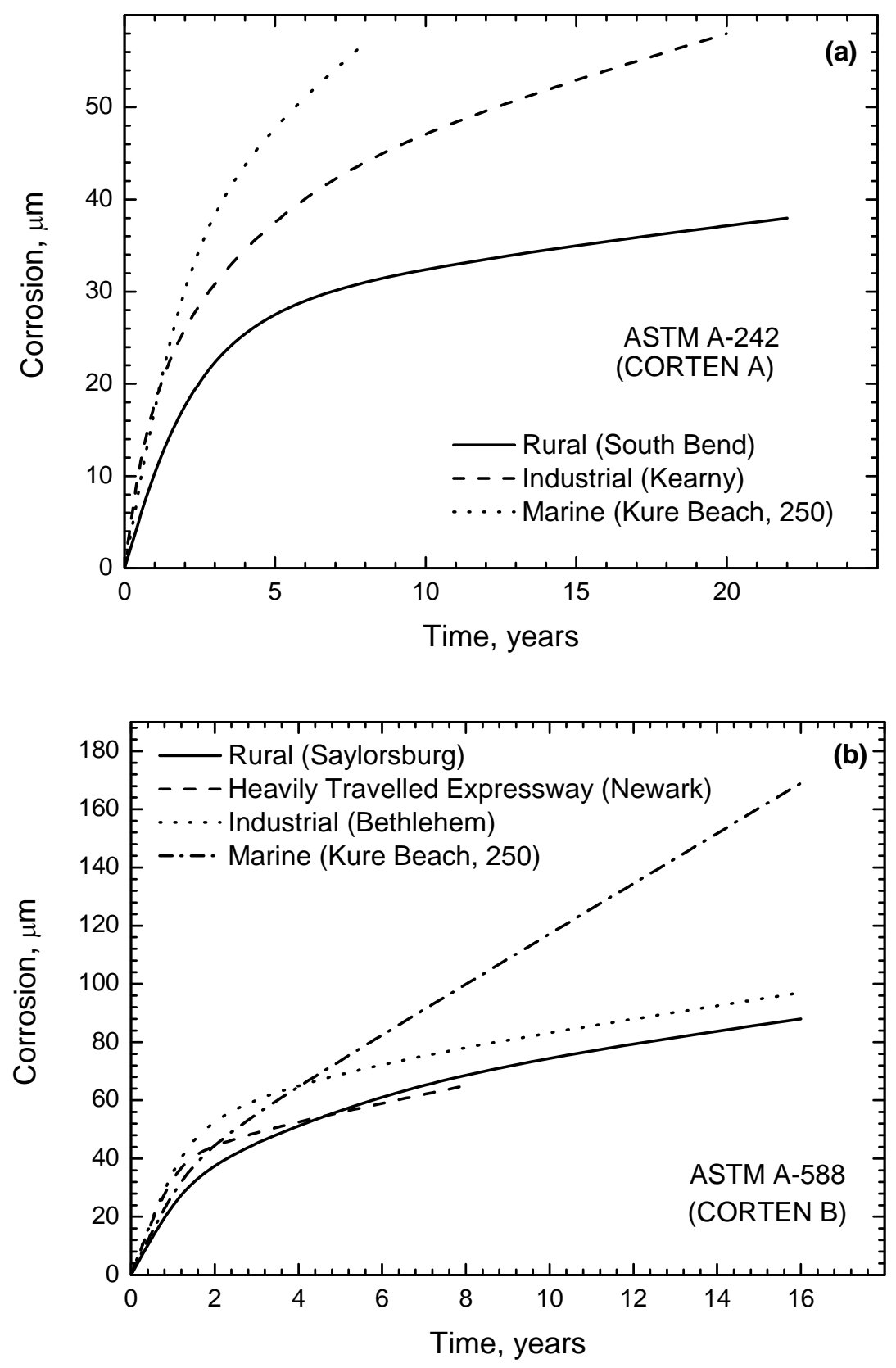

Figure 6 


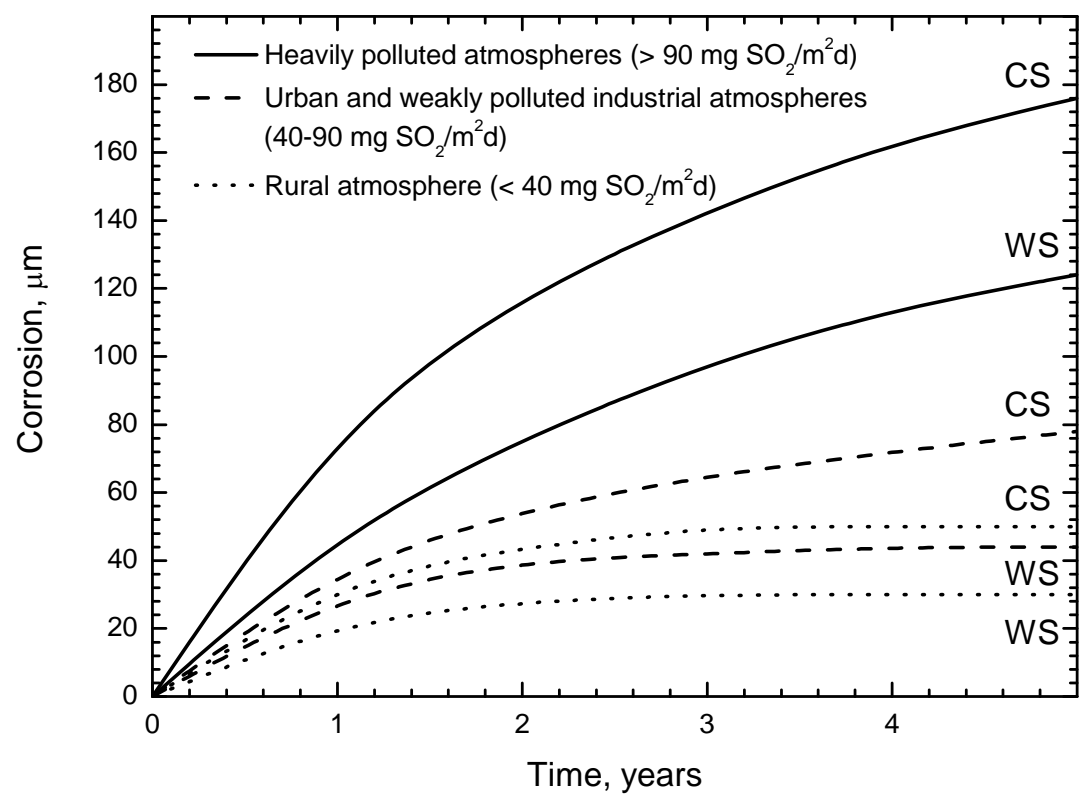

Figure 7 


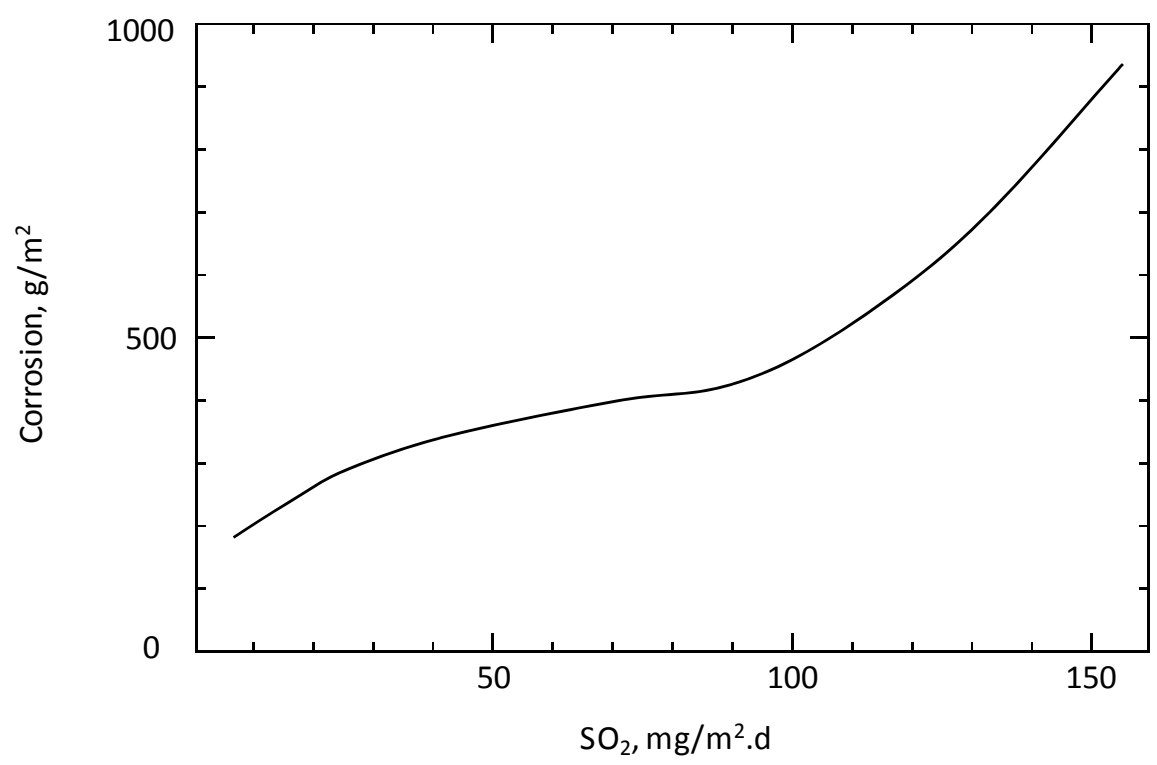

Figure 8 


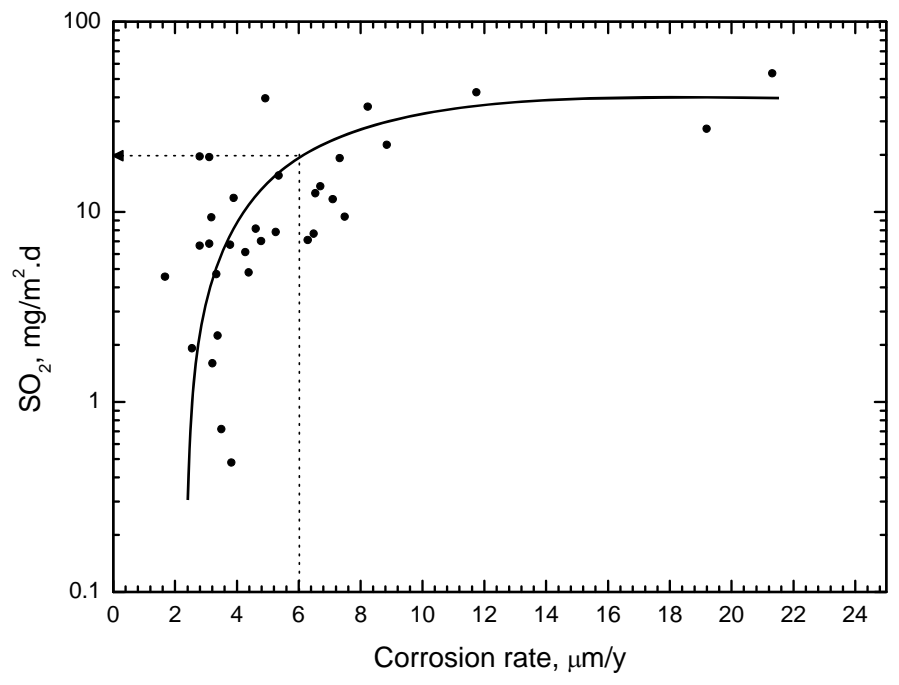

Figure 9 


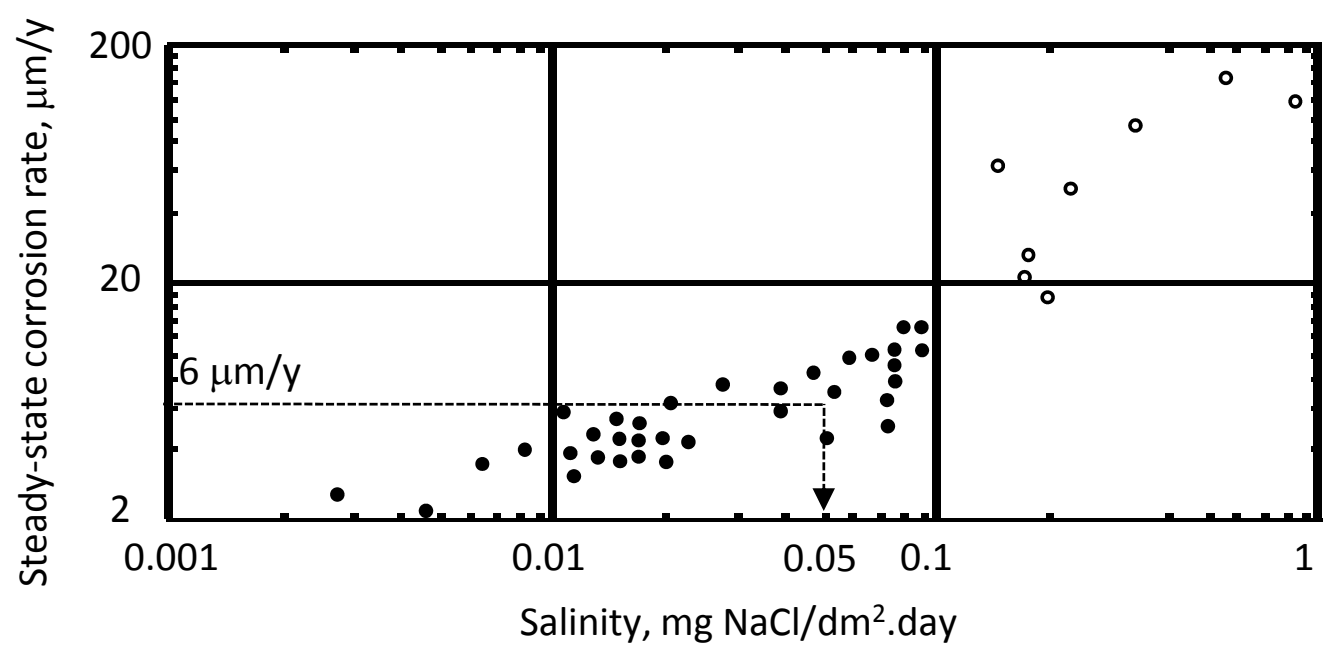

- Adherent rust layer (protective)

- Not adherent rust layer (non protective)

Figure 10 


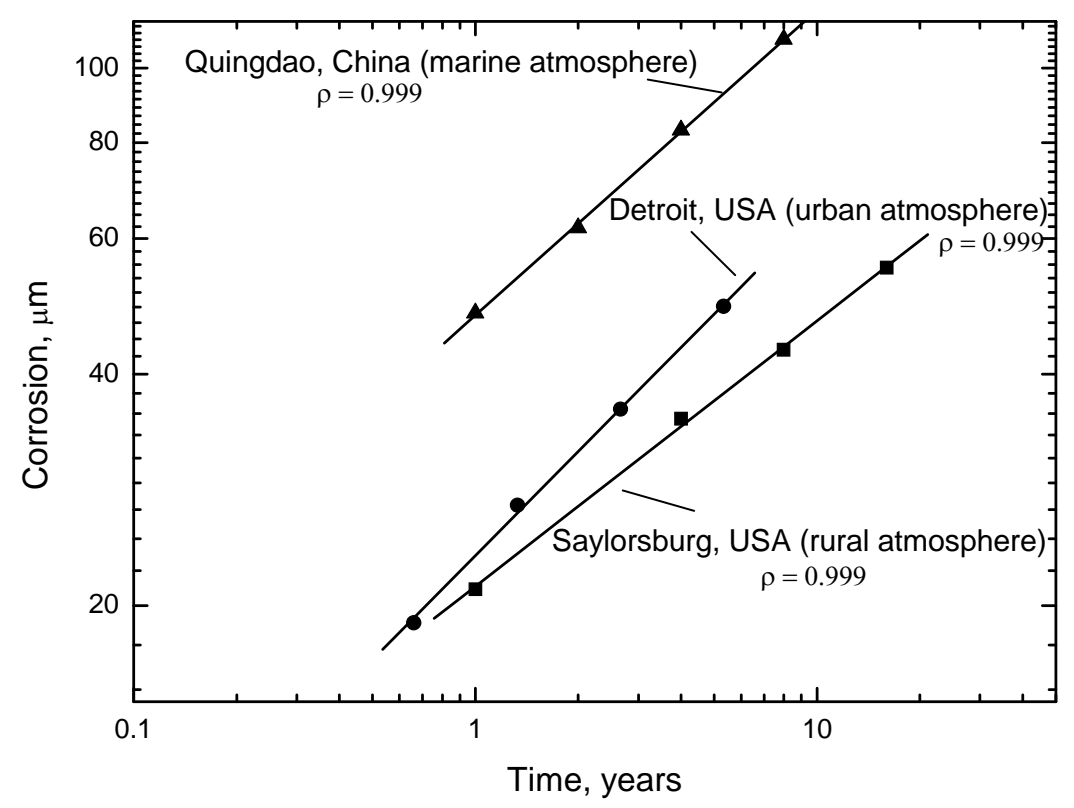

Figure 11 


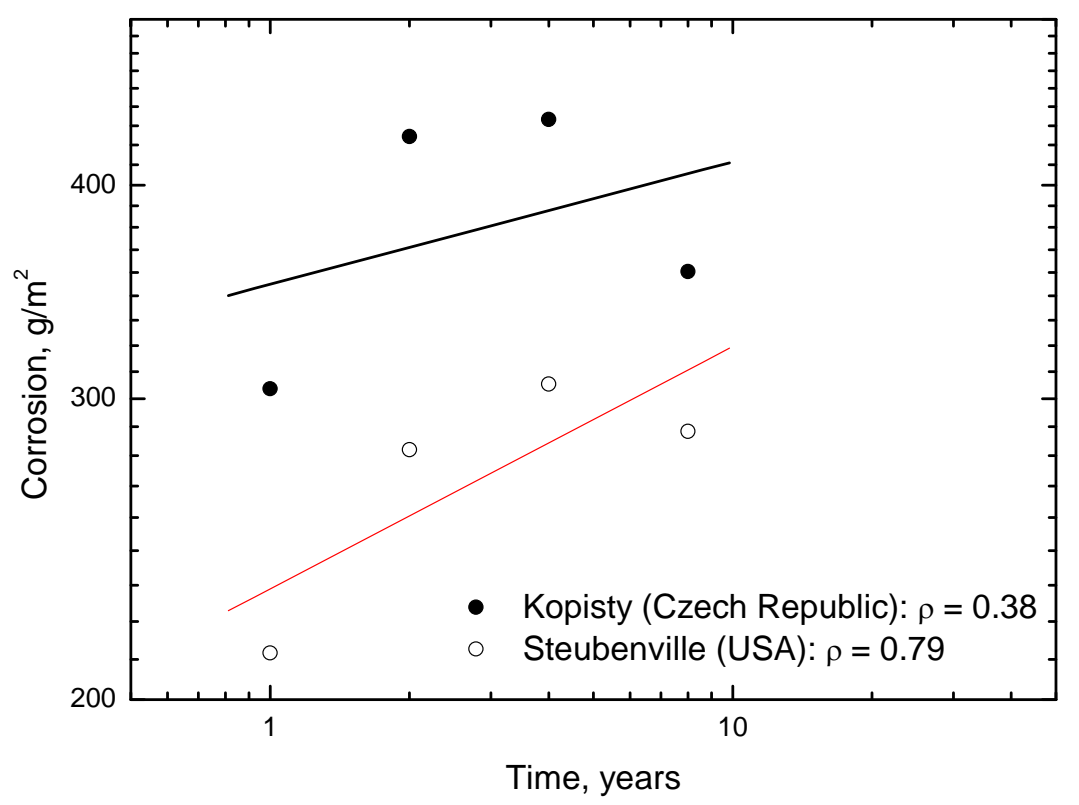

Figure 12 


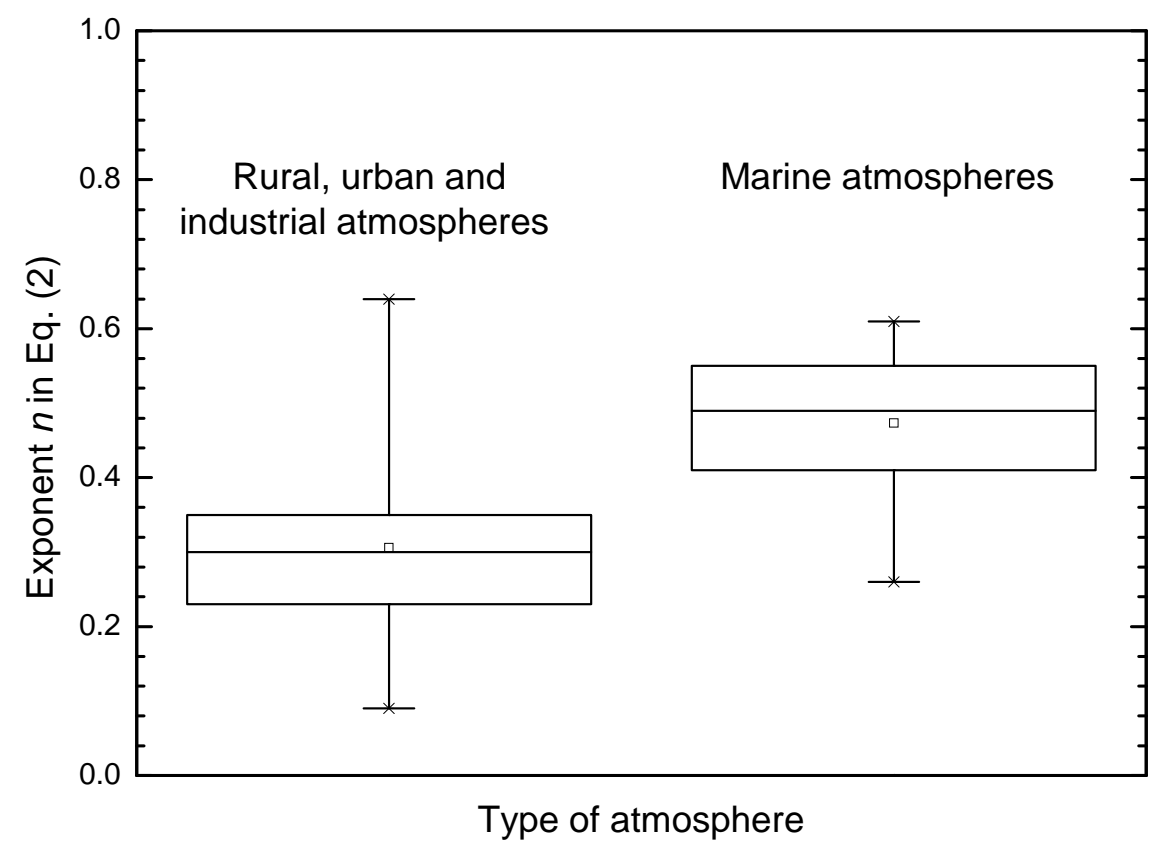

Figure 13 


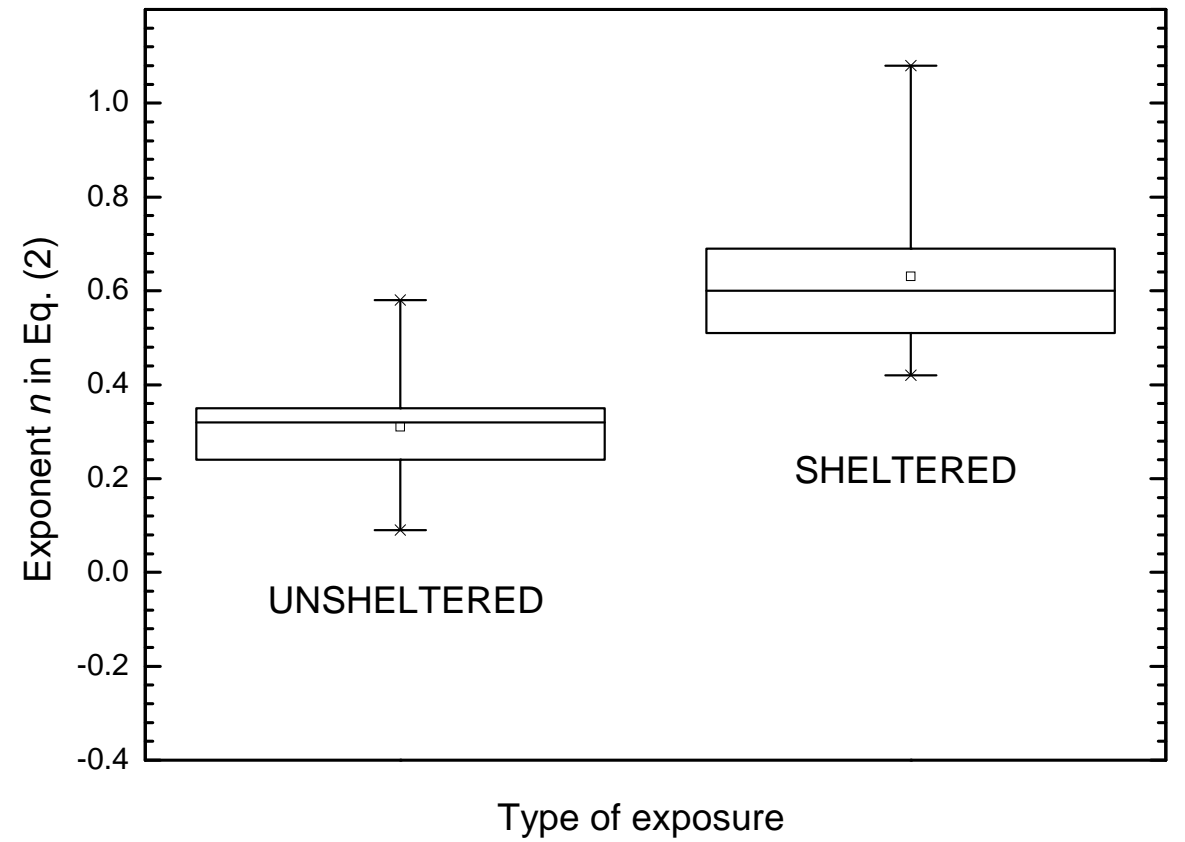

Figure 14 


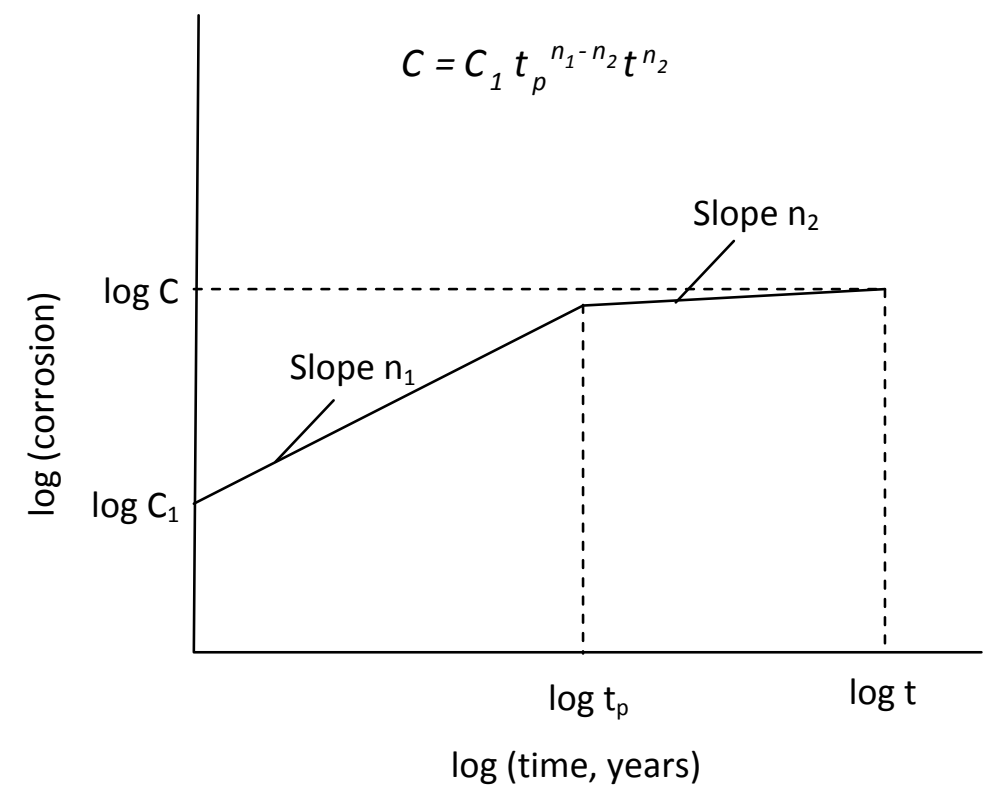

Figure 15 


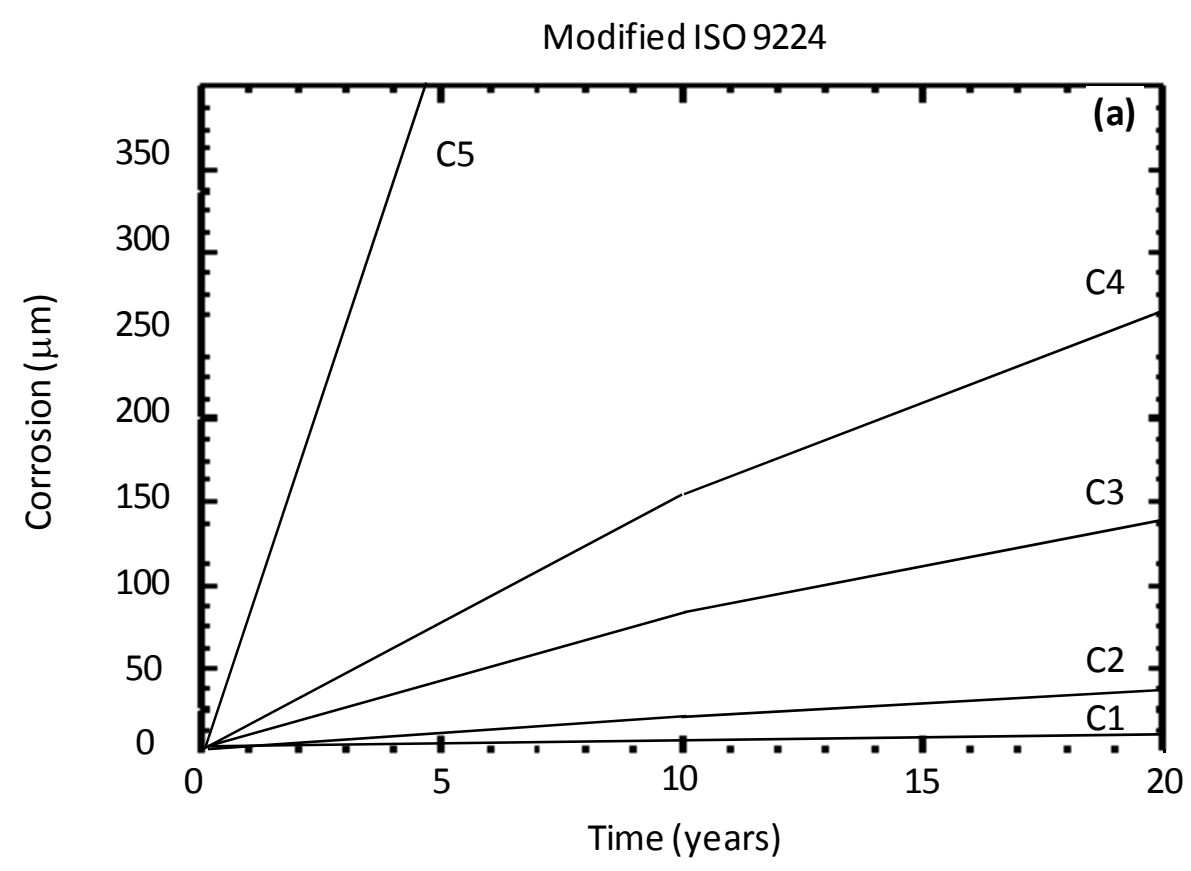

Modified ISO 9224 and Albrecht et al. adjustment for corrosivity category C3

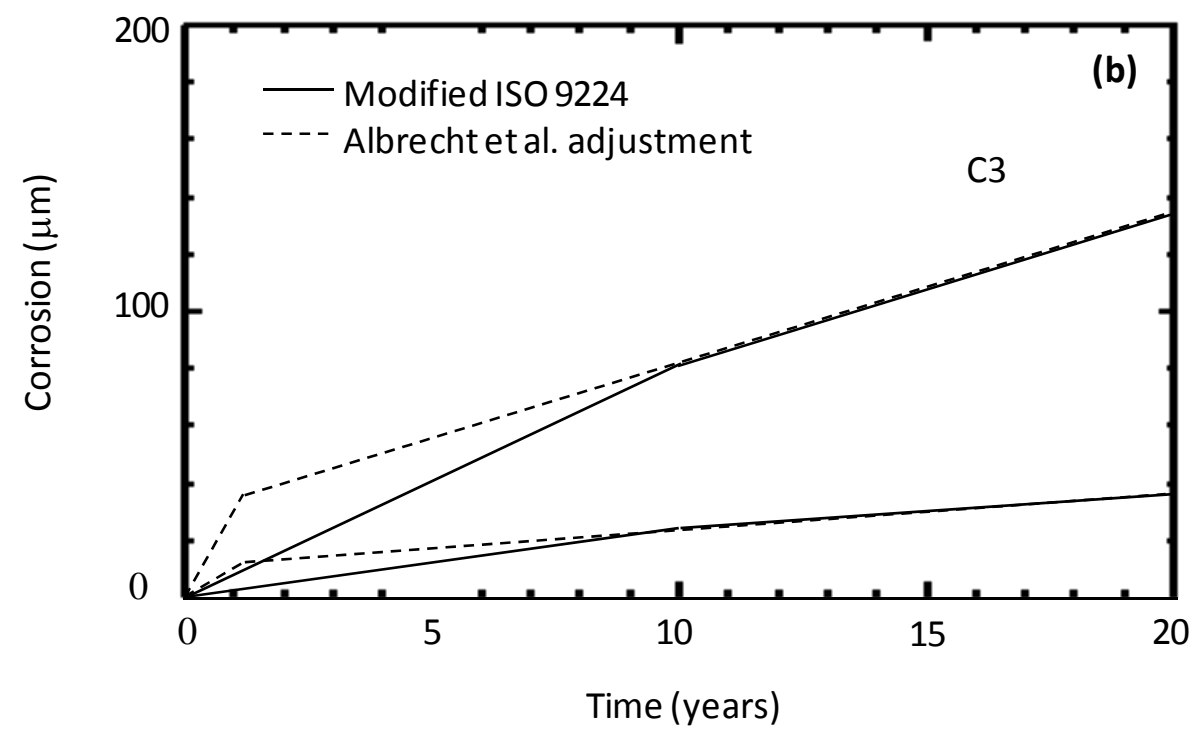

Figure 16 
Table 1. Chemical compositions (weight \%) of commonly used WS

\begin{tabular}{|c|c|c|c|c|c|c|c|c|c|}
\hline Weathering steel & $\mathrm{C}$ & $\mathrm{Si}$ & $\mathrm{Mn}$ & $P$ & $S$ & $\mathrm{Cu}$ & $\mathrm{Cr}$ & $\mathrm{Ni}$ & V \\
\hline $\begin{array}{c}\text { ASTM A-242 } \\
\text { (CORTEN A) [2] }\end{array}$ & $\leq 0.15$ & & $\leq 1.00$ & $\leq 0.15$ & $<0.05$ & $\geq 0.20$ & & & \\
\hline $\begin{array}{c}\text { Typical } \\
\text { concentrations }\end{array}$ & & & & $\leq 0.15$ & & $0.25-0.40$ & $0.50-0.80$ & $0.50-0.65$ & \\
\hline $\begin{array}{c}\text { ASTM A-588 Gr.A } \\
\text { (CORTEN B) [4] }\end{array}$ & $\leq 0.19$ & $0.30-0.65$ & $0.80-1.25$ & $\leq 0.04$ & $<0.05$ & $0.25-0.40$ & $0.40-0.65$ & $\leq 0.40$ & $0.02-0.10$ \\
\hline $\begin{array}{c}\text { Typical } \\
\text { concentrations }\end{array}$ & & & & $\leq 0.04$ & & $0.30-0.40$ & $0.60-1.00$ & $0.02-0.30$ & \\
\hline
\end{tabular}


Table 2. List of atmospheric corrosion exposure tests involving weathering steels carried out in different parts of the world. General characteristics of the tests

$\mathrm{R}=$ Rural, $\mathrm{I}=$ Industrial, $\mathrm{M}=$ Marine

\begin{tabular}{|c|c|c|c|c|c|}
\hline Country & Reference & Test site & $\begin{array}{c}\text { Type of } \\
\text { atmosphere }\end{array}$ & $\begin{array}{l}\text { Weathering } \\
\text { steel (ASTM) }\end{array}$ & $\begin{array}{c}\text { Max. exposure } \\
\text { time, years }\end{array}$ \\
\hline \multirow{4}{*}{ Belgium } & \multirow{4}{*}[22-23,49]{} & Eupen & $\mathrm{R}^{*}$ & \multirow{4}{*}{ A-242 } & 4 \\
\hline & & Lieja & $I^{*}$ & & 10 \\
\hline & & Ostende I & $M^{*}$ & & 10 \\
\hline & & Ostende II & $M^{*}$ & & 10 \\
\hline \multirow{7}{*}{ Brazil } & \multirow{7}{*}{ [24-25] } & Aracaju 1-3 & $M$ & \multirow{7}{*}{ A-588 } & 2 \\
\hline & & Betim & 1 & & 5 \\
\hline & & Canoas & I & & 5 \\
\hline & & Cubatao & I & & 5 \\
\hline & & Fortaleza & M & & 2 \\
\hline & & Madre de Deus & M & & 2 \\
\hline & & S. Mateus & $\mathrm{R}$ & & 5 \\
\hline Canada & [26] & Dorset & $\mathrm{R}^{*}$ & A-242 & 8 \\
\hline \multirow{7}{*}{ China } & \multirow{7}{*}[27-30,51-52]{} & Beijing & $\mathrm{U}^{*}$ & \multirow{7}{*}{ Other } & 8 \\
\hline & & Guangzhou & $\mathrm{R}^{*}$ & & 8 \\
\hline & & Jiangjin & I* & & 8 \\
\hline & & Qonghai & $\mathrm{R}^{*}$ & & 8 \\
\hline & & Quingdao & M-I* & & 8 \\
\hline & & Wanning & $M^{*}$ & & 8 \\
\hline & & Wuham & $\mathrm{U}^{*}$ & & 8 \\
\hline \multirow{4}{*}{ Czech Rep. } & \multirow{4}{*}[26,31-33]{} & Hurbanovo & $\mathrm{R}-\mathrm{U}^{*}$ & \multirow{4}{*}{$A-242$} & 10 \\
\hline & & Karsperske Hory & $\mathrm{R}^{*}$ & & 8 \\
\hline & & Kopisty & $I^{*}$ & & 8 \\
\hline & & Prague & U-I* & & 10 \\
\hline Estonia & [26] & Lahemaa & $\mathrm{R}^{*}$ & A-242 & 8 \\
\hline \multirow{3}{*}{ Finland } & \multirow{3}{*}{ [26] } & Ahtari & $\mathrm{R}^{*}$ & \multirow{3}{*}{ A-242 } & 8 \\
\hline & & Espoo & $\mathrm{U}^{*}$ & & 8 \\
\hline & & Helsinki & U-I* & & 8 \\
\hline \multirow{2}{*}{ France } & \multirow{2}{*}[22-23,49]{} & Biarritz & $M^{*}$ & \multirow{2}{*}{ A-242 } & 4 \\
\hline & & St Germain & $\mathrm{R}-\mathrm{U}^{*}$ & & 4 \\
\hline \multirow{12}{*}{ Germany } & \multirow{12}{*}{$\begin{array}{c}{[22-23,26,34-} \\
35,49]\end{array}$} & Aschaffenburg & $\mathrm{U}^{*}$ & & 8 \\
\hline & & Bottrop & ।* & & 8 \\
\hline & & Cuxhaven & M & & 8 \\
\hline & & Duisburg & 1 & & 16 \\
\hline & & Düsseldorf & $I^{*}$ & & 4 \\
\hline & & Essen & $\mathrm{R}^{*}$ & $A-242$ & 8 \\
\hline & & Gelsenkirchen & 1 & A-242 & 4 \\
\hline & & Langenfeld & $\mathrm{R}^{*}$ & & 8 \\
\hline & & Mülheim & I & & 8 \\
\hline & & Olpe & $\mathrm{R}$ & & 8 \\
\hline & & Garmisch-Partenkirchen & $\mathrm{R}^{*}$ & & 8 \\
\hline & & Waldhof-Laugenbrugge & $\mathrm{R}^{*}$ & & 8 \\
\hline & & Bari & $\mathrm{R}^{*}$ & & 4 \\
\hline & & Lasaccia & $\mathrm{R}^{*}$ & 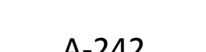 & 8 \\
\hline Italy & {$[22-23,26,49]$} & Milan & U-I* & $A-\angle 4 Z$ & 8 \\
\hline & & Rome & $\mathrm{U}^{*}$ & & 8 \\
\hline & & Venice & $\mathrm{U}^{*}$ & & 8 \\
\hline 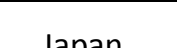 & {$[36-37]$} & Amagasaki & I* $^{*}$ & Other & 5,7 \\
\hline Japan & {$[36-3 /]$} & Kitakyushu & ।* & Other & 5 \\
\hline & & Birkenes & $\mathrm{R}^{*}$ & & 8 \\
\hline Norway & [26] & Borregaard & $I^{*}$ & $A-242$ & 8 \\
\hline & & Oslo & $\mathrm{U}^{*}$ & & 8 \\
\hline
\end{tabular}


Table 2 (continued)

\begin{tabular}{|c|c|c|c|c|c|}
\hline \multirow{6}{*}{ Netherlands } & \multirow{6}{*}[22-23,26,49]{} & Delft & $I^{*}$ & \multirow{6}{*}{$A-242$} & 4 \\
\hline & & Den Helder & $M^{*}$ & & 4 \\
\hline & & Eibergen & $\mathrm{R}^{*}$ & & 8 \\
\hline & & Vlaardingen & U-I* & & 8 \\
\hline & & Vredepeel & $\mathrm{R}^{*}$ & & 8 \\
\hline & & Wijnandsrade & $\mathrm{R}^{*}$ & & 8 \\
\hline \multirow{2}{*}{ Panama } & \multirow{2}{*}{ [38] } & Limon Bay & $M$ & \multirow{2}{*}{ A-242 } & 16 \\
\hline & & Miraflores Lock & $\mathrm{R}$ & & 16 \\
\hline Portugal & {$[26]$} & Lisbon & $\mathrm{U}^{*}$ & A-242 & 8 \\
\hline \multirow{2}{*}{ Romania } & \multirow{2}{*}[54]{} & Urban-Industrial & U-I & A-242 and & 20 \\
\hline & & Rural & $\mathrm{R}$ & A-588 & 20 \\
\hline Russia & [26] & Moscow & U-I* & 242 & 8 \\
\hline \multirow{3}{*}{ Spain } & \multirow{3}{*}[26]{} & Bilbao & $\mathrm{U}^{*}$ & \multirow{3}{*}{ A-242 } & 8 \\
\hline & & Madrid & $U^{*}$ & & 8 \\
\hline & & Toledo & $\mathrm{R}^{*}$ & & 8 \\
\hline \multirow{3}{*}{ Sweden } & \multirow{3}{*}[26]{} & Aspureten & $\mathrm{R}^{*}$ & \multirow{3}{*}{$A-242$} & 8 \\
\hline & & Stockholm (Centre) & $U^{*}$ & & 8 \\
\hline & & Stockholm (South) & $\mathrm{U}^{*}$ & & 8 \\
\hline \multirow{8}{*}{ Switzerland } & \multirow{8}{*}[55]{} & Bern & $U$ & \multirow{8}{*}{ A-242 } & 8 \\
\hline & & Cadenazzo & $\mathrm{R}$ & & 8 \\
\hline & & Davos & $\mathrm{R}$ & & 8 \\
\hline & & Dubendorf & $U$ & & 8 \\
\hline & & Harkingen & $U$ & & 8 \\
\hline & & Lagern & $\mathrm{R}$ & & 8 \\
\hline & & Payerne & $\mathrm{R}$ & & 8 \\
\hline & & Sion & $\mathrm{R}$ & & 8 \\
\hline \multirow{2}{*}{ Taiwan } & [39-40] & China Steel & $I^{*}$ & Other & 6 \\
\hline & {$[39-40]$} & Nat. Tsing. Hua Univ & $\mathrm{R}-\mathrm{U}^{*}$ & otner & 5 \\
\hline & & Clateringshowsloch & $\mathrm{R}$ & & 8 \\
\hline & & Lincoln Cathedral & $U^{*}$ & & 8 \\
\hline United & [22-23.26.49] & Rye & $\mathrm{M}^{*}$ & $4-242$ & 4 \\
\hline Kingdom & {$[\angle L-\angle 3, \angle 0,4 Y]$} & Stoke Orchard & $\mathrm{R}^{*}$ & $A-\angle 4 Z$ & 8 \\
\hline & & Stratford & $I^{*}$ & & 4 \\
\hline & & Wells Cathedral & $\mathrm{U}^{*}$ & & 8 \\
\hline & & Bayonne & 1 & A-242 & 18.1 \\
\hline & & Bethlehem & 1 & A-242/A-588 & 16 \\
\hline & & Black Island & M & A-242 & 9.1 \\
\hline & & Cincinnati & $U$ & A-242 & 5.3 \\
\hline & & Columbus & $U$ & A-242 & 10 \\
\hline & & Detroit & $U$ & $A-242$ & 5.3 \\
\hline & & East Chicago & 1 & A-242 & 20 \\
\hline & & Kearny & 1 & A-242/A-588 & 20 \\
\hline & & Kure Beach, 25m & M & A-242 & 7 \\
\hline & & Kure Beach, 250m & $M$ & A-242/A-588 & 16 \\
\hline & & Los Angeles & $U$ & A-242 & 5.3 \\
\hline USA & {$[12,19,26,41-$} & Newark & U-I & $A-242 / A-588$ & 8 \\
\hline & & Philadelphia & $U$ & A-242 & 5.3 \\
\hline & & Point Reyes & M & $A-242$ & 7 \\
\hline & & Potter County & $\mathrm{R}$ & A-242/A-588 & 16 \\
\hline & & Rankin & $U$ & A-242 & 17 \\
\hline & & Research Triangle Park & $\mathrm{R}^{*}$ & A-242 & 8 \\
\hline & & Saylorsburg & $\mathrm{R}$ & $A-242 / A-588$ & 16 \\
\hline & & South Bend & $\mathrm{R}$ & A-242 & 22 \\
\hline & & State College & $\mathrm{R}$ & A-242 & 7 \\
\hline & & Steubenville & $I^{*}$ & $A-242$ & 8 \\
\hline & & Washington & $\mathrm{U}$ & A-242 & 5.3 \\
\hline & & Whiting & $\mathrm{I}$ & A-242 & 7 \\
\hline
\end{tabular}


Table 3. Rust layer stabilisation times and steady-state corrosion rates of weathering steels exposed in atmospheres with different corrosivity categories. Non-marine atmospheres (rural, urban and industrial)

\begin{tabular}{|c|c|c|c|c|c|c|c|}
\hline $\begin{array}{l}\text { ISO corrosivity } \\
\text { category [57] }\end{array}$ & $\begin{array}{c}1^{\text {st }} \text { year CS } \\
\text { corrosion, } \mu \mathrm{m}\end{array}$ & Test site & Country & $\begin{array}{c}\text { Stabilization } \\
\text { time, years }\end{array}$ & $\begin{array}{c}\text { Steady-state } \\
\text { corrosion rate, } \\
\mu \mathrm{m} / \mathrm{y}\end{array}$ & $\begin{array}{c}\text { Max. } \\
\text { exposure } \\
\text { time, years }\end{array}$ & WS (ASTM) \\
\hline \multirow{9}{*}{$\mathrm{C} 2$} & 16.8 & Ahtari & Finland & $7-8$ & 4.4 & 8 & $A-242$ \\
\hline & 18.7 & Aspureten & Sweden & $6-7$ & 5.7 & 8 & $A-242$ \\
\hline & 19.0 & Dorset & Canada & $7-8$ & 3.8 & 8 & $A-242$ \\
\hline & 22.4 & R. Triangle & USA & $5-6$ & 6.9 & 8 & $A-242$ \\
\hline & 22.7 & Rome & Italy & $7-8$ & 4.1 & 8 & $A-242$ \\
\hline & 23.6 & Lahemaa & Estonia & $6-7$ & 5.6 & 8 & $A-242$ \\
\hline & 24.0 & Potter C. & USA & $7-8$ & 4.2 & 16 & $A-242$ \\
\hline & 24.0 & Potter C. & USA & $7-8$ & 8.7 & 16 & $A-588$ \\
\hline & 24.7 & Birkenes & Norway & $5-6$ & 7.6 & 8 & $A-242$ \\
\hline \multirow{30}{*}{ C3 } & 27.1 & Aschaffenburg & Germany & $7-8$ & 5.9 & 8 & $A-242$ \\
\hline & 27.3 & Steubenville & USA & $7-8$ & 5.2 & 8 & $A-242$ \\
\hline & 28.3 & Madrid & Spain & $6-7$ & 4.3 & 8 & $A-242$ \\
\hline & 29.0 & Kearny1 & USA & $6-7$ & 3.9 & 16 & $A-242$ \\
\hline & 29.0 & Kearny1 & USA & $7-8$ & 5.1 & 16 & $A-588$ \\
\hline & 29.2 & Oslo & Norway & $6-7$ & 6.1 & 8 & $A-242$ \\
\hline & 29.6 & Eibergen & Netherlands & $6-7$ & 7.1 & 8 & $A-242$ \\
\hline & 29.9 & Casaccia & Italy & $6-7$ & 6.6 & 8 & $A-242$ \\
\hline & 29.9 & Clatteringshaws & UK & $5-6$ & 9.7 & 8 & $A-242$ \\
\hline & 30.0 & Saylorsburg & USA & $7-8$ & 5.4 & 16 & $A-242$ \\
\hline & 30.0 & Saylorsburg & USA & $6-7$ & 9.7 & 16 & $A-588$ \\
\hline & 30.3 & Stockholm S & Sweden & $6-7$ & 7.5 & 8 & $A-242$ \\
\hline & 31.2 & Venice & Italy & $6-7$ & 7.6 & 8 & A-242 \\
\hline & 33.0 & Wijnandsrade & Netherlands & $6-7$ & 7.4 & 8 & $A-242$ \\
\hline & 33.5 & Stockholm C & Sweden & $7-8$ & 7.1 & 8 & $A-242$ \\
\hline & 33.6 & Waldhof & Germany & $6-7$ & 9.3 & 8 & $A-242$ \\
\hline & 34.5 & Espoo & Finland & $6-7$ & 8.1 & 8 & A-242 \\
\hline & 34.8 & Helsinki & Finland & $7-8$ & 8.9 & 8 & $A-242$ \\
\hline & 36.1 & Vredepeel & Netherlands & $6-7$ & 8.8 & 8 & $A-242$ \\
\hline & 37.2 & South Bend & USA & $10-11$ & 3.4 & 22 & $A-242$ \\
\hline & 37.3 & Langenfeld & Germany & $6-7$ & 8.9 & 8 & $A-242$ \\
\hline & 39.1 & Stoke Orchard & UK & $6-7$ & 9.6 & 8 & $A-242$ \\
\hline & 40.1 & Lincoln Cath. & UK & $4-5$ & 19.8 & 8 & $A-242$ \\
\hline & 42.0 & Hurbanovo & Czech R. & $7-8$ & 5.9 & 10 & $A-242$ \\
\hline & 43.0 & Olpe & Germany & $6-7$ & 9.7 & 8 & $A-242$ \\
\hline & 43.6 & Essen & Germany & $6-7$ & 9.1 & 8 & A-242 \\
\hline & 43.8 & Vlaardingen & Netherlands & $6-7$ & 9.7 & 8 & $A-242$ \\
\hline & 46.6 & Milan & Italy & $6-7$ & 6.8 & 8 & A-242 \\
\hline & 47.5 & Bottrop & Germany & $7-8$ & 8.2 & 8 & $A-242$ \\
\hline & 50.0 & Newark1 & USA & $5-6$ & 10.3 & 8 & $A-588$ \\
\hline \multirow{9}{*}{ C4 } & 51.0 & Columbus & USA & $6-7$ & 10.7 & 10 & A-242 \\
\hline & 54.8 & Borregaard & Norway & $5-6$ & 13.7 & 8 & A-242 \\
\hline & 64.0 & Lieja & Bélgica & $4-5$ & 19.2 & 10 & $A-242$ \\
\hline & 67.0 & Withing & USA & $6-7$ & 11.4 & 7 & $A-242$ \\
\hline & 69.0 & Bethlehem2 & USA & $6-7$ & 10.0 & 10 & $A-242$ \\
\hline & 71.0 & Bayonne & USA & $4-5$ & 12.4 & 18 & $A-242$ \\
\hline & 72.0 & Rankin & USA & $5-6$ & 12.1 & 10 & $A-242$ \\
\hline & 76.0 & Bethlehem1 & USA & $7-8$ & 5.8 & 16 & $A-242$ \\
\hline & 76.0 & Bethlehem1 & USA & $7-8$ & 9.7 & 16 & $A-588$ \\
\hline \multirow{7}{*}{ C5 } & 80.0 & Newark2 & USA & $5-6$ & 12.1 & 7 & $A-242$ \\
\hline & 86.0 & Prague & Czech R. & $6-7$ & 10.2 & 10 & $A-242$ \\
\hline & 88.0 & Mülheim & Germany & $5-6$ & 20.0 & 8 & $A-242$ \\
\hline & 114.0 & Duisburg & Germany & $5-6$ & 29.5 & 16 & $A-242$ \\
\hline & 116.0 & Kearny3 & USA & $8-9$ & 4.9 & 20 & $A-242$ \\
\hline & 119.0 & Kearny2 & USA & $6-7$ & 5.4 & 20 & $A-588$ \\
\hline & 119.0 & Kearny2 & USA & $4-5$ & 7.7 & 7.5 & $A-242$ \\
\hline
\end{tabular}


Table 4. Rust layer stabilisation times and steady-state corrosion rates of weathering steels exposed in atmospheres with different corrosivity categories. Marine atmospheres

\begin{tabular}{|c|c|c|c|c|c|c|c|}
\hline $\begin{array}{l}\text { ISO corrosivity } \\
\text { category [57] }\end{array}$ & $\begin{array}{c}1^{\text {st }} \text { year } \mathrm{CS} \\
\text { corrosion, } \mu \mathrm{m}\end{array}$ & Test site & Country & $\begin{array}{l}\text { Stabilization } \\
\text { time, years }\end{array}$ & $\begin{array}{c}\text { Steady-state } \\
\text { corrosion rate, } \\
\mu \mathrm{m} / \mathrm{y}\end{array}$ & $\begin{array}{c}\text { Max. } \\
\text { exposure } \\
\text { time, years }\end{array}$ & WS (ASTM) \\
\hline \multirow{10}{*}{ C3 } & 28.5 & Lisbon & Portugal & $6-7$ & 6.9 & 8 & A-242 \\
\hline & 32.2 & Wells Cathedral & UK & $5-6$ & 9.8 & 8 & $A-242$ \\
\hline & 35.0 & Miraflores Lock & USA & $6-7$ & 11.3 & 16 & A-242 \\
\hline & 35.0 & Miraflores Lock & USA & $6-7$ & 12.2 & 16 & A-242 \\
\hline & 39.0 & Kure Beach2 & USA & $5-6$ & 11.0 & 16 & $A-242$ \\
\hline & 39.0 & Kure Beach2 & USA & $5-6$ & 14.4 & 16 & $A-588$ \\
\hline & 40.0 & Kure Beach1 & USA & $5-6$ & 10.4 & 16 & $A-242$ \\
\hline & 40.0 & Kure Beach1 & USA & $4-5$ & 17.4 & 16 & A-588 \\
\hline & 41.0 & Bilbao & Spain & $6-7$ & 7.3 & 8 & $A-242$ \\
\hline & 47.9 & Kure Beach5 & USA & $6-7$ & 8.8 & 8 & A-242 \\
\hline \multirow{4}{*}{ C4 } & 52.5 & Kure Beach 4 & USA & $4-5$ & 15.1 & 16 & A-242 \\
\hline & 64.0 & Limon Bay & USA & $6-7$ & 19.5 & 16 & $A-242$ \\
\hline & 64.0 & Limon Bay & USA & $7-8$ & 15.8 & 16 & A-242 \\
\hline & 65.0 & Cuxhaven & Germany & $5-6$ & 15.3 & 8 & A-242 \\
\hline \multirow{2}{*}{ C5 } & 95.0 & Point Reyes & USA & $6-7$ & 16.1 & 7 & $A-242$ \\
\hline & 140.0 & Kure Beach 3 & USA & $5-6$ & 20.0 & 7 & $A-242$ \\
\hline
\end{tabular}


Table 5. Rust layer stabilisation times and steady-state corrosion rates of weathering steels exposed in atmospheres with different corrosivity categories [26]. Unshelter versus shelter exposure

\begin{tabular}{|c|c|c|c|c|c|c|c|c|}
\hline \multirow[b]{2}{*}{$\begin{array}{c}\text { ISO } \\
\text { corrosivity } \\
\text { category [57] }\end{array}$} & \multirow[b]{2}{*}{$\begin{array}{c}1^{\text {st }} \text { year } \mathrm{CS} \\
\text { corrosion, } \mu \mathrm{m}\end{array}$} & \multirow[b]{2}{*}{ Test site } & \multirow[b]{2}{*}{ Country } & \multirow[b]{2}{*}{$\begin{array}{l}\mathrm{SO}_{2} \\
\mu \mathrm{g} / \mathrm{m}^{3}\end{array}$} & \multicolumn{2}{|c|}{ Unshelter } & \multicolumn{2}{|c|}{ Shelter } \\
\hline & & & & & $\begin{array}{l}\text { Stabilization } \\
\text { time, years }\end{array}$ & $\begin{array}{c}\text { Steady-state } \\
\text { corrosion } \\
\text { rate, } \mu \mathrm{m} / \mathrm{y}\end{array}$ & $\begin{array}{c}\text { Stabilization } \\
\text { time, years }\end{array}$ & $\begin{array}{c}\text { Steady-state } \\
\text { corrosion } \\
\text { rate, } \mu \mathrm{m} / \mathrm{y}\end{array}$ \\
\hline \multirow{4}{*}{$\mathrm{C} 2$} & 19.0 & Dorset & Canada & 2.8 & $7-8$ & 3.8 & $7-8$ & 3.7 \\
\hline & 22.4 & R. Triangle & USA & 9.8 & $5-6$ & 6.9 & $5-6$ & 6.9 \\
\hline & 22.7 & Rome & Italy & 24.5 & $7-8$ & 4.1 & $6-7$ & 3.3 \\
\hline & 23.6 & Lahemaa & Estonia & 0.6 & $6-7$ & 5.6 & $7-8$ & 4.4 \\
\hline \multirow{18}{*}{ C3 } & 27.1 & Aschaffenburg & Germany & 14.8 & $7-8$ & 5.9 & $6-7$ & 4.6 \\
\hline & 28.3 & Madrid & Spain & 11.7 & $6-7$ & 4.3 & $5-6$ & 4.1 \\
\hline & 29.6 & Eibergen & Netherlands & 7.7 & $6-7$ & 7.1 & $4-5$ & 6.2 \\
\hline & 29.9 & Casaccia & Italy & 6.0 & $6-7$ & 6.6 & $5-6$ & 5.4 \\
\hline & 30.3 & Stockholm S & Sweden & 8.4 & $6-7$ & 7.5 & $7-8$ & 4.2 \\
\hline & 31.2 & Venice & Italy & 15.7 & $6-7$ & 7.6 & $3-4$ & 9.0 \\
\hline & 33.0 & Wijnandsrade & Netherlands & 10.2 & $6-7$ & 7.4 & $4-5$ & 6.5 \\
\hline & 33.5 & Stockholm C & Sweden & 8.5 & $7-8$ & 7.1 & $7-8$ & 4.2 \\
\hline & 33.6 & Waldhof & Germany & 9.6 & $6-7$ & 9.3 & $4-5$ & 9.1 \\
\hline & 34.5 & Espoo & Finland & 8.8 & $6-7$ & 8.1 & $5-6$ & 6.3 \\
\hline & 34.8 & Helsinki & Finland & 11.8 & $7-8$ & 8.9 & $4-5$ & 10.1 \\
\hline & 36.1 & Vredepeel & Netherlands & 8.9 & $6-7$ & 8.8 & $4-5$ & 8.3 \\
\hline & 37.3 & Langenfeld & Germany & 19.4 & $6-7$ & 8.9 & $6-7$ & 6.6 \\
\hline & 39.1 & Stoke Orchard & UK & 14.6 & $6-7$ & 9.6 & $6-7$ & 8.7 \\
\hline & 40.1 & Lincoln Cath. & UK & 17.6 & $4-5$ & 19.8 & $2-3$ & 16.2 \\
\hline & 43.6 & Essen & Germany & 24.0 & $6-7$ & 9.1 & $3-4$ & 11.4 \\
\hline & 43.8 & Vlaardingen & Netherlands & 28.2 & $6-7$ & 9.7 & $2-3$ & 14.8 \\
\hline & 47.5 & Bottrop & Germany & 44.8 & $7-8$ & 8.2 & $3-4$ & 10.7 \\
\hline C4 & 54.8 & Borregaard & Norway & 34.2 & $5-6$ & 13.7 & $3-4$ & 26.8 \\
\hline
\end{tabular}


Table 6. Relation $(R)$ between weathering steel corrosion rate and plain carbon steel corrosion rate at the rust layer stabilisation time

\begin{tabular}{|c|c|c|c|c|c|}
\hline & $\begin{array}{c}\text { ISO corrosivity } \\
\text { category [57] }\end{array}$ & $\begin{array}{c}1^{\text {st }} \text { year } \mathrm{CS} \\
\text { corrosion, } \mu \mathrm{m}\end{array}$ & Country & Test site & $\begin{array}{l}\mathrm{R}\left(\mathrm{C}_{\mathrm{ws}} / \mathrm{C}_{\mathrm{cs}}\right) \text { at the } \\
\text { stabilization time }\end{array}$ \\
\hline \multirow{20}{*}{ 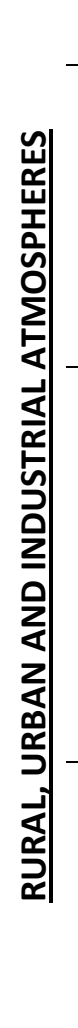 } & C2 & 24.0 & USA & Potter County & 0.33 \\
\hline & \multirow{6}{*}{ C3 } & 29.0 & USA & Kearny 1 & 0.42 \\
\hline & & 30.0 & USA & Saylorsburg & 0.32 \\
\hline & & 37.0 & USA & South Bend & 0.28 \\
\hline & & 42.0 & Czech Rep. & Hurbanovo & 0.43 \\
\hline & & 43.0 & Germany & Olpe & 0.57 \\
\hline & & & & Ave. & 0.40 \\
\hline & \multirow{8}{*}{ C4 } & 51.0 & USA & Columbus & 0.49 \\
\hline & & 64.0 & Belgium & Lieja & 0.39 \\
\hline & & 67.0 & USA & Withing & 0.58 \\
\hline & & 69.0 & USA & Bethlehem 2 & 0.38 \\
\hline & & 71.0 & USA & Bayonne & 0.38 \\
\hline & & 72.0 & USA & Rankin & 0.34 \\
\hline & & 76.0 & USA & Bethlehem 1 & 0.35 \\
\hline & & & & Ave. & 0.42 \\
\hline & \multirow{5}{*}{ C5 } & 80.0 & USA & Newark 2 & 0.51 \\
\hline & & 86.0 & Czech Rep. & Prague & 0.41 \\
\hline & & 88.0 & Germany & Mülheim & 0.37 \\
\hline & & 114.0 & Germany & Duisburg & 0.47 \\
\hline & & & & Ave. & 0.44 \\
\hline \multirow{8}{*}{ 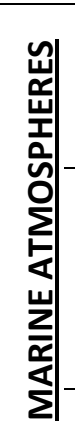 } & \multirow{3}{*}{ C3 } & 35.0 & Panama & Miraflores Lock 1 & 0.52 \\
\hline & & 35.0 & Panama & Miraflores Lock 2 & 0.56 \\
\hline & & & & Ave. & 0.54 \\
\hline & \multirow{4}{*}{ C4 } & 53.0 & USA & Kure Beach 4 & 0.41 \\
\hline & & 64.0 & USA & Limon Bay & 0.53 \\
\hline & & 65.0 & Germany & Cuxhaven & 0.47 \\
\hline & & & & Ave. & 0.47 \\
\hline & $\mathrm{C5}$ & 140.0 & USA & Kure Beach 3 & 0.29 \\
\hline
\end{tabular}


Table 7. Values of exponent $n$ and correlation coefficient in bi-logarithmic plots of the power function $\left(C=A t^{n}\right)$. Non-marine atmospheres

\begin{tabular}{|c|c|c|c|c|c|}
\hline $\begin{array}{l}\text { ISO corrosivity } \\
\text { category [57] }\end{array}$ & $\begin{array}{c}1^{\text {st }} \text { year CS } \\
\text { corrosion, } \mu \mathrm{m}\end{array}$ & Test site & Country & Exponent $n$ & $\begin{array}{l}\text { Correlation } \\
\text { coefficient }\end{array}$ \\
\hline \multirow{14}{*}{ C2 } & 5.7 & Toledo & Spain & 0.47 & 0.955 \\
\hline & 14.1 & Los Angeles & USA & 0.35 & 0.996 \\
\hline & 16.8 & Ahtari & Finland & 0.47 & 0.969 \\
\hline & 16.9 & Garmisch & Germany & 0.23 & 0.886 \\
\hline & 18.7 & Aspureten & Sweden & 0.37 & 0.994 \\
\hline & 19.0 & Dorset & Canada & 0.26 & 0.916 \\
\hline & 21.4 & Cincinati & USA & 0.27 & 0.998 \\
\hline & 22.4 & R. Triangle & USA & 0.35 & 0.995 \\
\hline & 22.7 & Rome & Italy & 0.19 & 0.938 \\
\hline & 23.1 & Moscow & Russia & 0.25 & 0.874 \\
\hline & 23.6 & Lahemaa & Estonia & 0.26 & 0.979 \\
\hline & 24.0 & Potter County & USA & 0.27 & 0.977 \\
\hline & 24.0 & Washington & USA & 0.33 & 0.998 \\
\hline & 24.7 & Birkenes & Norway & 0.40 & 0.996 \\
\hline \multirow{32}{*}{ C3 } & 27.1 & Aschaffenburg & Germany & 0.33 & 0.946 \\
\hline & 27.3 & Steubenville & USA & 0.14 & 0.793 \\
\hline & 28.2 & Philadelphia & USA & 0.29 & 0.996 \\
\hline & 28.3 & Madrid & Spain & 0.11 & 0.854 \\
\hline & 28.5 & Kasperske Hory & Czech R. & 0.33 & 0.866 \\
\hline & 29.0 & Kearny1 & USA & 0.22 & 0.948 \\
\hline & 29.2 & Oslo & Norway & 0.24 & 0.970 \\
\hline & 29.6 & Eibergen & Netherlands & 0.30 & 0.959 \\
\hline & 29.9 & Casaccia & Italy & 0.30 & 0.993 \\
\hline & 29.9 & Clatteringshaws & UK & 0.43 & 0.993 \\
\hline & 30.0 & Saylorsburg & USA & 0.35 & 0.999 \\
\hline & 30.2 & Detroit & USA & 0.45 & 0.999 \\
\hline & 30.3 & Stockholm S & Sweden & 0.24 & 0.992 \\
\hline & 31.2 & Venice & Italy & 0.34 & 0.987 \\
\hline & 33.0 & Wijnandsrade & Netherlands & 0.31 & 0.974 \\
\hline & 33.5 & Stockholm C & Sweden & 0.24 & 0.940 \\
\hline & 33.6 & Waldhof & Germany & 0.39 & 0.991 \\
\hline & 34.5 & Espoo & Finland & 0.38 & 0.992 \\
\hline & 34.8 & Helsinki & Finland & 0.35 & 0.957 \\
\hline & 36.1 & Vredepeel & Netherlands & 0.35 & 0.983 \\
\hline & 37.3 & Langenfeld & Germany & 0.32 & 0.998 \\
\hline & 38.0 & South Bend & USA & 0.16 & 0.980 \\
\hline & 39.1 & Stoke Orchard & UK & 0.35 & 0.992 \\
\hline & 40.1 & Lincoln Cath. & UK & 0.58 & 0.999 \\
\hline & 42.0 & Hurbanovo & Czech R. & 0.14 & 0.867 \\
\hline & 43.0 & Olpen & Germany & 0.51 & 0.987 \\
\hline & 43.6 & Essen & Germany & 0.32 & 0.983 \\
\hline & 43.8 & Vlaardingen & Netherlands & 0.30 & 0.981 \\
\hline & 45.0 & State College & USA & 0.22 & 0.919 \\
\hline & 46.6 & Milan & Italy & 0.09 & 0.888 \\
\hline & 47.5 & Bottrop & Germany & 0.28 & 0.947 \\
\hline & 50.0 & Newark1 & USA & 0.26 & 0.999 \\
\hline
\end{tabular}


Table 7 (continued)

\begin{tabular}{cccccc}
\hline & 51.0 & Columbus & USA & 0.36 & 0.965 \\
& 54.8 & Borregaard & Norway & 0.35 & 0.998 \\
& 55.8 & Prague & Czech R. & 0.22 & 0.867 \\
& 64.0 & Lieja & Bélgica & 0.64 & 0.998 \\
& 67.0 & Whiting & USA & 0.17 & 0.947 \\
& 69.0 & Bethlehem2 & USA & 0.17 & 0.950 \\
& 70.9 & Kopisty & Czech R. & 0.07 & 0.380 \\
& 71.0 & Bayonne & USA & 0.31 & 0.996 \\
& 72.0 & Rankin & USA & 0.32 & 0.978 \\
& 76.0 & Bethlehem1 & USA & 0.26 & 0.999 \\
& 80.0 & Newark2 & USA & 0.15 & 0.974 \\
\hline & 86.0 & Prague & Czech R. & 0.18 & 0.933 \\
& 88.0 & Mülheim & Germany & 0.50 & 0.998 \\
& 100.0 & Kopisty & Czech Rep. & 0.51 & 0.999 \\
& 114.0 & Duisburg & Germany & 0.61 & 0.996 \\
& 116.0 & Kearny3 & USA & 0.30 & 1.000 \\
& 119.0 & Kearny2 & USA & 0.15 & 0.973 \\
& 210.0 & Gelsenkirchen & Germany & 0.50 & 0.998 \\
\hline
\end{tabular}


Table 8. Values of exponent $n$ and correlation coefficient in bi-logarithmic plots of the power function $\left(C=A t^{n}\right)$. Marine atmospheres

\begin{tabular}{cccccc}
\hline $\begin{array}{c}\text { ISO corrosivity } \\
\text { category [57] }\end{array}$ & $\begin{array}{c}1^{\text {st }} \text { year CS } \\
\text { corrosion, } \mu \mathrm{m}\end{array}$ & Test site & Country & Exponent $n$ & $\begin{array}{c}\text { Correlation } \\
\text { coefficient }\end{array}$ \\
\hline \multirow{4}{*}{ C3 } & 28.5 & Lisbon & Portugal & 0.31 & 0.988 \\
& 32.2 & Wells Cathedral & UK & 0.38 & 0.989 \\
& 35.0 & Miraflores Lock 1 & USA & 0.53 & 1.000 \\
& 35.0 & Miraflores Lock 2 & USA & 0.52 & 0.998 \\
& 39.0 & Kure Beach2 & USA & 0.996 \\
& 40.0 & Kure Beach1 & USA & 0.55 & 0.992 \\
& 41.0 & Bilbao & Spain & 0.26 & 0.973 \\
C4 & 47.9 & Kure Beach5 & USA & 0.45 & 0.986 \\
\hline & 52.5 & Kure Beach4 & USA & 0.49 & 0.998 \\
& 64.0 & Limon Bay 1 & USA & 0.51 & 0.998 \\
& 64.0 & Limon Bay 2 & Un & 0.48 & 1.000 \\
C5 & 65.0 & Cuxhaven & Germany & 0.56 & 0.996 \\
\hline & 95.0 & Point Reyes & USA & 0.46 & 0.989 \\
& 100.0 & Ostende 2 & Belgium & 0.72 & 0.999 \\
& 140.0 & Kure Beach3 & USA & 0.41 & 0.996 \\
& 181.0 & Ostende 1 & Belgium & 1.04 & 1.000 \\
\hline
\end{tabular}


Table 9. Average values of exponent $n$ in bi-logarithmic plots of the power function $(C=$ $A t^{n}$ ) for plain carbon steel (CS) and weathering steel (WS) in non-marine (ruralurban-industrial) and marine atmospheres

\begin{tabular}{ccccccc}
\hline & \multicolumn{3}{c}{ Non marine (Rural-Urban-Industrial) } & \multicolumn{3}{c}{ Marine atmospheres } \\
\cline { 2 - 7 } Steel & $\begin{array}{c}\text { Number of } \\
\text { atmospheres }\end{array}$ & $\begin{array}{c}n \\
\text { data }\end{array}$ & $\begin{array}{c}\text { Range of } n \\
\text { in Eq. (2) }\end{array}$ & $\begin{array}{c}\text { Number of } \\
\text { data }\end{array}$ & $\begin{array}{c}n \\
\text { Ave. }\end{array}$ & $\begin{array}{c}\text { Range of } n \\
\text { in Eq. (2) }\end{array}$ \\
\hline $\begin{array}{c}\text { CS (from } \\
\text { ref. [92]) }\end{array}$ & 25 & 0.49 & $0.26-0.76$ & 13 & 0.73 & $0.37-0.98$ \\
\hline $\begin{array}{c}\text { WS (from } \\
\text { tables 7-8) }\end{array}$ & 58 & 0.33 & $0.11-0.64$ & 16 & 0.48 & $0.26-0.72$ \\
\hline
\end{tabular}


Table 10. Dose-response functions for weathering steel in unsheltered and sheltered exposures [86]

\begin{tabular}{lc}
\hline Material & Mass loss, $g / \mathrm{m}^{2}$ \\
\hline Weathering steel (unsheltered) & $\mathrm{ML}=34\left[\mathrm{SO}_{2}\right]^{0.33} \exp \{0.020 \mathrm{Rh}+\mathrm{f}(\mathrm{T})\} \mathrm{t}^{0.13}$ \\
\hline Weathering steel (sheltered) & $\mathrm{ML}=8.2\left[\mathrm{SO}_{2}\right]^{0.24} \exp \{0.025 \mathrm{Rh}+\mathrm{f}(\mathrm{T})\} \mathrm{t}^{0.66}$ \\
\hline where: $\mathrm{t}=$ exposure time (years); $\mathrm{Rh}=$ relative humidity $(\%) ; \mathrm{T}=$ average annual temperature \\
$\left({ }^{\circ} \mathrm{C}\right) ; \mathrm{f}(\mathrm{T})=\mathrm{a}(\mathrm{T}-10)$ when $\mathrm{T}<10^{\circ} \mathrm{C}$, otherwise $\mathrm{b}(\mathrm{T}-10)$, with $\mathrm{a}, \mathrm{b}$ being constant values depending \\
on the specific metal; $\mathrm{SO}_{2}=$ sulfur dioxide concentration $\left(\mu \mathrm{g} / \mathrm{m}^{3}\right)$ \\
\hline
\end{tabular}

